\title{
Cholinergic and GABAergic Inputs Drive Patterned Spontaneous Motoneuron Activity before Target Contact
}

\author{
Louise D. Milner and Lynn T. Landmesser \\ Department of Neurosciences, Case Western Reserve University, School of Medicine, Cleveland, Ohio 44106
}

Patterned spontaneous electrical activity has been demonstrated in a number of developing neural circuits and has been proposed to play a role in refining connectivity once axons reach their targets. Using an isolated spinal cord preparation, we have found that chick lumbosacral motor axons exhibit highly regular bursts of activity from embryonic day 4 (E4) (stage 24-25), shortly after they exit the spinal cord and while still en route toward their target muscles. Similar bursts could be evoked by stimulating descending pathways at cervical or thoracic levels. Unlike older embryonic cord circuits, the major excitatory transmitter driving activity was not glutamate but acetylcholine, acting primarily though nicotinic non- $\alpha 7$ receptors. The circuit driving bursting was surprisingly robust and plastic, because bursting was only transiently blocked by cho- linergic antagonists, and following recovery, was now driven by GABAergic inputs. Permanent blockade of spontaneous activity was only achieved by a combination of cholinergic antagonists and bicuculline, a GABA $\mathrm{A}_{\mathrm{A}}$ antagonist. The early occurrence of patterned motor activity suggests that it could be playing a role in either peripheral pathfinding or spinal cord circuit formation and maturation. Finally, the characteristic differences in burst parameters already evident between different motoneuron pools at E4 would require that the combination of transcription factors responsible for specifying pool identity to have acted even earlier.

Key words: motoneurons; spontaneous neural activity; rhythmicity; nicotinic receptors; GABA; cholinergic inputs; spinal cord interneurons; embryonic networks
The nervous system consists of complex neural circuits initially constructed during development by a combination of intrinsic molecular cues that guide neurons to their targets and activitydependent cues that fine tune those connections (for review, see Goodman and Shatz, 1993; Katz and Shatz, 1996). The role of activity in circuit formation was first explored in the visual system in which visual experience appeared to drive the fine tuning of cortical connections (Hubel and Wiesel, 1970). However, more recently, it has become clear that many developing circuits, including both visual and motor, are spontaneously active before environmental experience (Bekoff et al., 1975; O'Donovan and Landmesser, 1987; Galli and Maffei, 1988; Mooney et al., 1996) and that such spontaneous activity can also refine connections (Shatz and Stryker 1988; Ruthazer and Stryker, 1996; Weliky and Katz, 1997; Penn et al., 1998).

In the motor system, activity is important for modulating target innervation. Both the extent of initial synaptogenesis (Ding et al., 1983; Dahm and Landmesser, 1991) and the later refinement of connections are regulated by activity (O'Brien et al., 1978; Thompson, 1985; Greensmith and Vrbova, 1991). Activity is also necessary for maturation of muscle targets, including proper secondary myogenesis (Harris, 1981; McLennan, 1983; Fredette and Landmesser, 1991). In the chick, spontaneous EMG activity

Received Nov. 9, 1998; revised Jan. 6, 1999; accepted Feb. 4, 1999.

This work was supported by National Institutes of Health Grant NS 19640 from National Institute of Neurological Diseases and Stroke, a McKnight Senior Investigator Award, and National Institute of Child Health and Human Development Predoctoral Training Grant T32 HD07104. We thank Victor Rafuse, Marianne Usiak, Shilpi Banerjee, and Brian Halavisky for helpful comments on this manuscript. We are especially grateful to Marianne Usiak who participated in some of the early experiments.

Correspondence should be addressed to Dr. Lynn T. Landmesser, Department of Neurosciences, Case Western Reserve University, School of Medicine, 10090 Euclid Avenue, Cleveland, OH 44106-4975.

Copyright (ㄷ) 1999 Society for Neuroscience $\quad 0270-6474 / 99 / 193007-16 \$ 05.00 / 0$ has been shown to exist as soon as motor neurons make functional contacts with target muscles (Bekoff et al., 1975; O’Donovan and Landmesser, 1987), resulting in spontaneous recurrent episodes of limb movements (Hamburger and Balaban, 1963). Neither sensory nor supraspinal input is necessary for these movements (Hamburger et al., 1966), indicating that activity of neurons within the spinal cord is sufficient to generate both the rhythmicity and pattern of movement.

In chick, the pattern and frequency of spontaneous motoneuron bursting episodes changes in a systematic way from initial target innervation [stages 29-30; embryonic day 6 (E6)] until after the motoneuron cell death period (stages 36-38; E10-E12) (O'Donovan and Landmesser, 1987). Pharmacological characterization of the cord circuit at later stages (E10-E12) has revealed that the excitatory transmitter glutamate is primarily responsible for driving the frequency of bursting episodes, whereas GABA, glycine, and ACh modify burst structure (Barry and O'Donovan, 1987; Sernagor et al., 1995; Chub and O’Donovan, 1998). However, the circuit exhibits considerable plasticity, for if glutamate transmission is blocked, spontaneous bursting recovers but is now driven by GABAergic connections (Chub and O'Donovan, 1998).

Because the nature of the circuit driving the earliest spontaneous activity occurring before target contact was unknown, we characterized early activity by recording from muscle nerves that were growing toward their targets. We show that motoneurons exhibit spontaneous recurrent episodes of bursting activity as early as E4 (stages 24-25). Unlike later stages, early activity appears to be driven primarily by cholinergic circuits, with minor roles from GABA and glutamate. These results indicate that, not only do motoneurons exhibit patterned activity earlier than previously shown, but that the circuit responsible undergoes a switch in transmitters during the second week of gestation. The major changes in activity and pharmacology coincided with target con- 
tact, suggesting that target influences may play a role in circuit maturation.

\section{MATERIALS AND METHODS}

Nerve recordings. All recordings of spontaneous motor nerve activity were made in White Leghorn chick embryos between stages 24 and 29.5 (Hamburger and Hamilton, 1951). Nerves were recorded in an in vitro spinal cord-hindlimb preparation as described previously (Landmesser and O'Donovan, 1984). Briefly, embryos were removed from the egg, decapitated, eviscerated, and placed in cool oxygenated Tyrode's solution. A ventral laminectomy was performed to expose the spinal cord and to allow oxygen to diffuse to the motoneurons. Muscle nerves were exposed by carefully removing the skin and surrounding limb connective tissue with a fine tungsten needle. After dissection, Tyrode's solution was warmed to $27^{\circ} \mathrm{C}$ for the duration of the experiment. Nerves were recorded from using extra fine-tip suction electrodes pulled from polyethylene tubing (PE-190; Clay Adams, Parsippany, NJ). By applying a light suction, the tips of growing muscle nerves were pulled into the electrode and a tight seal was established (Fig. $1 A$ ). Activity was recorded continuously on an analog tape (Vetter, Rebersburg, PA) and was displayed on an oscilloscope (R5030; Tektronix, Beaverton, OR) and chart recorder (Gould Inc, Cleveland, $\mathrm{OH}$ ). In some cases, a single electrical pulse was given to the spinal cord to induce bursting. Stimuli were administered using a standard stimulator (S88; Grass, Quincy, MA) that was isolated from ground with a stimulator isolation unit (Grass PSIU6B).

Drug treatments. Neurochemicals and receptor blockers were bath applied in the in vitro spinal cord-hindlimb preparation using a pump that superfused circulated oxygenated Tyrode's solution over the preparation. Each drug was evaluated either alone or in combination with other drugs for its effect on spontaneous bursting activity. The drugs were applied for a minimum of $20 \mathrm{~min}$, and their effect on spontaneous activity was evaluated by quantifying the change in burst frequency, number of bursts per episode, and burst structure. As shown in Figure $1 B$, episodes of bursting activity consisting of one or more bursts (depending on the stage) occurred every several minutes. The interepisode interval was used to quantify the frequency of episodes, and the lengths of bursts and of interburst intervals were also measured in some cases. When comparing different drug treatments, 10 or more episodes were measured, and the data were displayed as mean \pm SE. Except where indicated, a given drug treatment was performed on two or more embryos with similar results, and, in most cases, drugs were washed until burst parameters returned to control values (several minutes to 1-2 $\mathrm{hr}$ depending on the drug).

A list of the drugs used includes the following: cholinergic receptor blockers: d-tubocurarine (dTC), atropine, dihydro-B-erythroidine (DHBE), $\alpha$-bungarotoxin, and methyllycoconitine (MLA); cholinergic agonists: nicotine and carbachol; acetylcholinesterase inhibitor: eserine; GABA receptor blockers: bicuculline and phaclofen; GABA agonist: muscimol; GABA reuptake blocker: nipecotic acid; glutamate receptor blockers: APV, CNQX, and kyurinate; glutamate agonists: glutamate and kainate; glutamate reuptake blocker: dihydrokainate (DHK); serotonin: 5-hydroxytryptamine; gap junction blockers: octanol and carbenoxolone. The effects of low-calcium $(0.2 \mathrm{~mm}) /$ high-magnesium $(7 \mathrm{~mm})$ Tyrode's solution or normal calcium $(2 \mathrm{~mm})$ /high-magnesium $(12 \mathrm{~mm})$ Tyrode's solution were tested to determine the contribution of synaptic input on spontaneous activity.

\section{RESULTS}

\section{Development of spontaneous bursting activity}

Previous studies had inferred that chick limb motoneurons were spontaneously active in ovo by E6 (stages 28.5-29) because this activity resulted in recurrent episodes of hindlimb movements (Hamburger and Balaban, 1963). This was later confirmed by recordings in ovo (Ripley and Provine, 1972; Bekoff et al., 1975; Bekoff, 1976) and in an in vitro spinal cord-hindlimb preparation (Landmesser and O'Donovan, 1984; O'Donovan and Landmesser, 1987). These studies showed that motoneurons exhibit spontaneous bursts of activity and that muscle contractions and thus limb movements do not occur in the absence of activation by motoneurons. To determine whether motoneurons were spontaneously bursting while growing toward their targets, we used an in
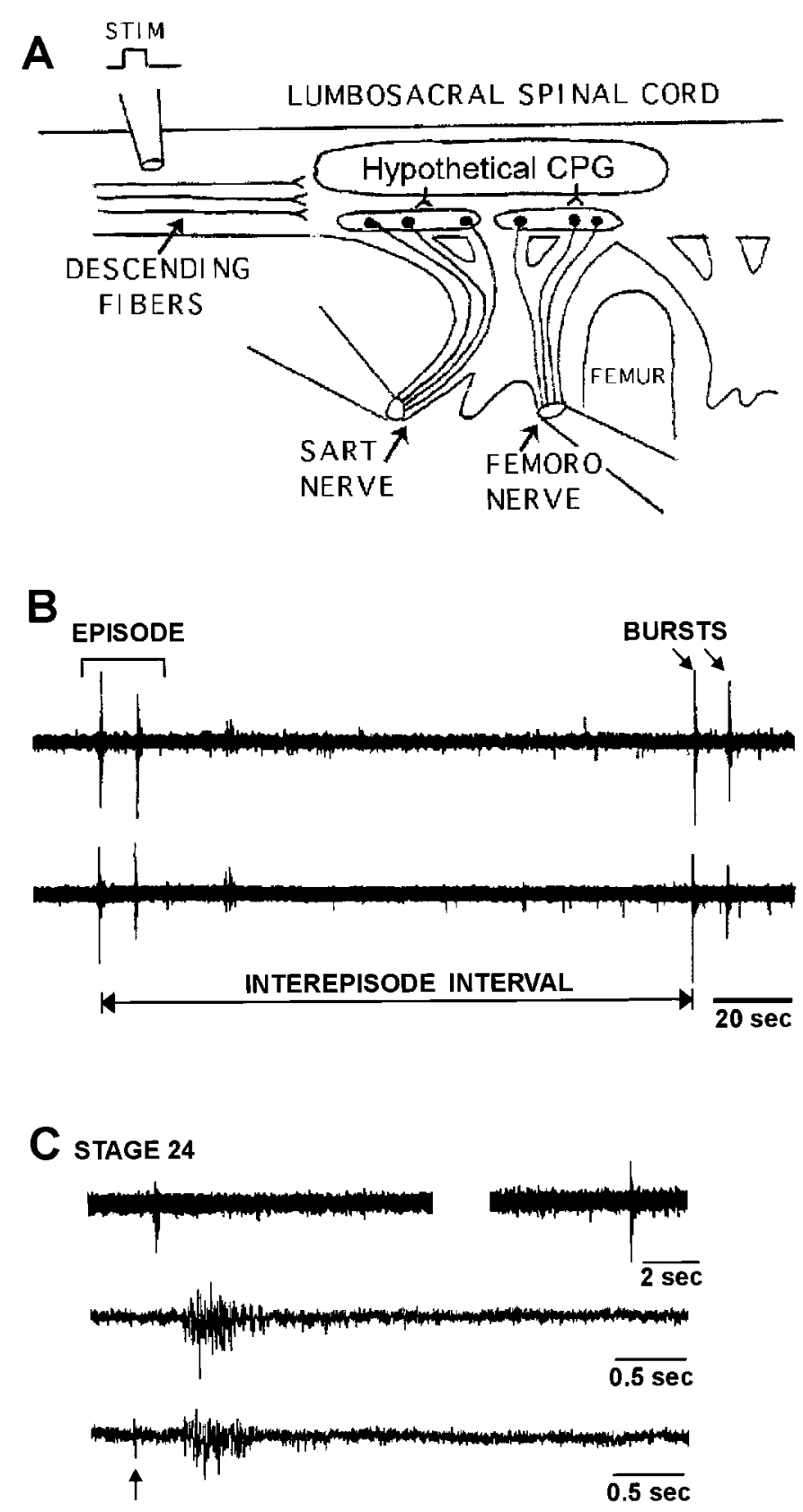

Figure 1. Motoneurons exhibit spontaneous episodes of bursting as they grow toward their targets. $A$, Schematic of the motor circuit in the chick lumbosacral spinal cord. Patterned motor activity is generated by local circuits in the cord (hypothetical $C P G$ ) and can be initiated by stimulating descending inputs from the rostral cord. Nerve recordings from specific muscle nerves were made using tight-fitting suction electrodes. In most figures, we have paired records from an extensor motor pool on the top trace with a flexor motor pool on the bottom trace. B, Example of spontaneous activity from the femorotibialis (top trace) and obturator (bottom trace) muscle nerves from a stage 25 embryo. Bursting activity occurred in episodes (bracket) containing multiple bursts (arrows). At stage 25 , episodes occurred regularly, $\sim 1-2$ min apart (interepisode inter$v a l)$. $C$, The earliest activity was recorded from the sciatic nerve at early stage 24 , when each episode contained a single burst and occurred every 3 min (top trace). The two bottom traces on an expanded time scale show that a burst evoked by stimulation of descending input from more rostral cord levels (bottom trace, arrow marks stimulus artifact) was similar to those occurring spontaneously (middle trace). $C P G$, Central pattern generator; SART, sartorius; FEMORO, femorotibialis. 
A stage 25

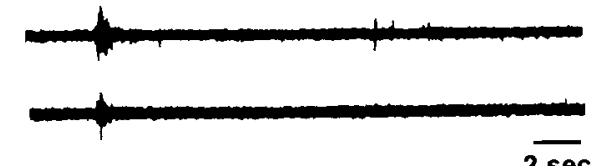

$\overline{2 \mathrm{sec}}$

B STAGE 25.5

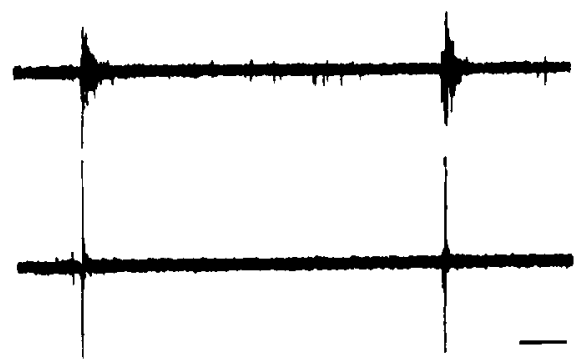

C stage 28

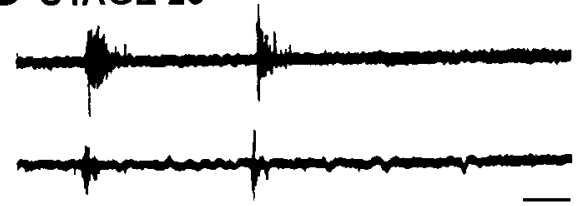

D STAGE 28.5

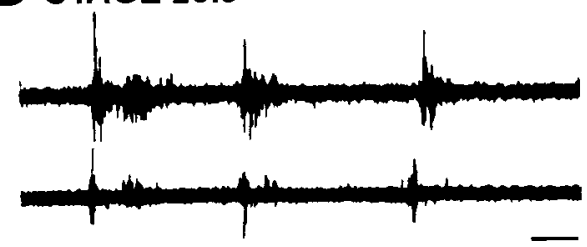

E

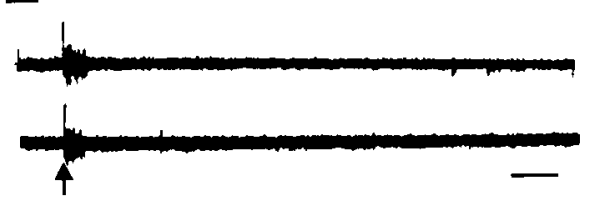

$F$
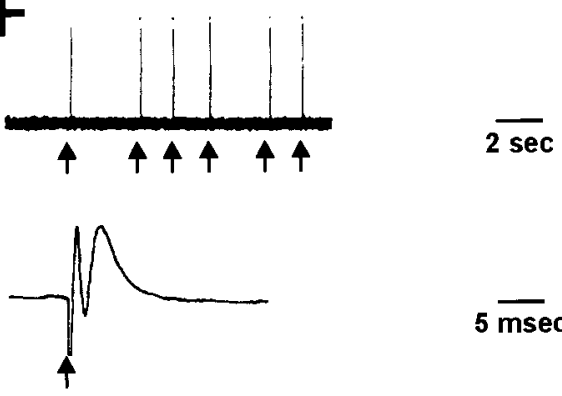

$5 \overline{\mathrm{msec}}$

G

INTERVAL BETWEEN EPISODES (MIN)

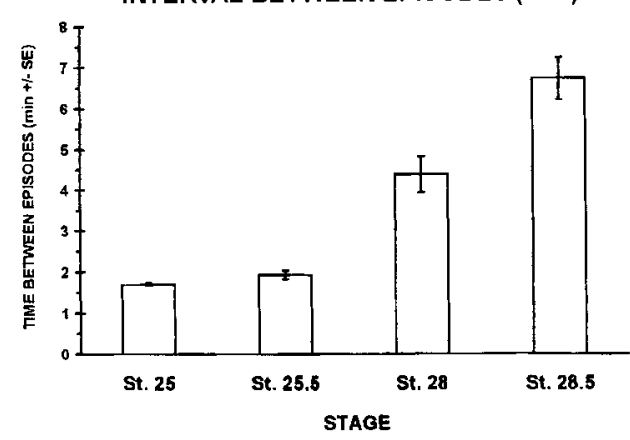

Figure 2. Developmental changes in bursting activity recorded from muscle nerves from stages 25-28.5. A, At stage 25 , each episode consists of a single burst, and characteristic differences between motoneuron pools are already apparent; the ischioflexorius/caudilioflexorius nerve (top trace) has longer duration bursts than the sartorius nerve (bottom trace). Extensors (top trace) and flexors (bottom trace) are activated synchronously. $B$, At stage 25.5 , a second burst routinely occurs in each episode of activity, and differences in burst characteristics between muscle nerves are more distinct. Top trace, FEMORO nerve. Bottom trace, SART nerve. $C$, Stage 28 bursting patterns are similar to those at stage 25.5. Top trace, FEMORO nerve; bottom trace, SART nerve. $D$, At stage 28.5, bursting characteristics changed more dramatically, with a third or fourth burst occurring in each episode and with significant increases in burst duration of both extensors (top trace, FEMORO nerve) and flexors (bottom trace, SART nerve). $E$, Bursting can be elicited at stage 25 by stimulation of the rostral spinal cord (arrow marks stimulus). $F$, In the presence of low-calcium/highmagnesium Tyrode's solution, spontaneous activity is eliminated, and stimulation of the rostral cord (top trace) does not elicit a burst (arrows mark stimulus artifacts). However, direct stimulation of the motoneurons causes a compound action potential with a short latency (bottom trace, arrow marks stimulus artifact) but does not elicit a burst. $G$, Graph showing that the frequency of spontaneous bursting episodes, plotted as the interval between episodes in min-

utes, at different stages declines with increasing developmental age. Frequency measurements shown are from the embryos in $A-D$. Each $b a r$ represents the data from a single embryo, representative of that stage (mean $\pm \mathrm{SE}$ ). Traces from $A, E$, and $F$ are from the same embryo. SART, Sartorius; FEMORO, femorotibialis. Calibration: $A-E, 2 \mathrm{sec} ; F$, top, $2 \mathrm{sec} ; F$, bottom, 5 msec.

vitro spinal cord-hindlimb preparation to record from the growing tips of muscle nerves with tight-fitting suction electrodes as soon as they emerged from the plexus as individual entities (Fig. 1 $A, B$ ).

As early as stage 24 (E4), when motor axons have just begun to bundle together (Fig. $1 A$ ) after a period of defasciculation in the plexus region (Tang et al., 1994), we found that they exhibit spontaneous recurrent episodes of patterned bursting, consisting of a single short burst of $\sim 500 \mathrm{msec}$ every $3.1 \pm 0.33 \mathrm{~min}$ (mean $\pm \mathrm{SE}$ ). Examples of such bursts (Fig. 1C) show that even at this early stage, stimulation of the cervical cord (bottom trace, arrow) is able to elicit a burst that is very similar to those occurring spontaneously (middle trace). Because of the difficulty in recording from the relatively defasciculated motor axons at this stage, we characterized early activity in more detail at stages 25-25.5, $\sim 12 \mathrm{hr}$ later, when motor axons had just refasciculated into individual muscle nerves.

At this stage, motoneurons produced a single burst every 1-2 min (Fig. 2A,G). Motor axons to flexor and extensor muscles burst simultaneously rather than in the alternating manner characteristic of more mature patterns of activity (O'Donovan and Landmesser, 1987; O’Donovan, 1989). However, even at this early stage, different pools of motoneurons could be distinguished by their unique pattern of activity. Specifically, flexor motoneu- rons, such as the sartorius (Fig. $2 A$, bottom trace), had shorter bursts than extensor motoneurons, such as the caudilioflexorius/ ischioflexorius (Fig. 2A, top trace) or the femorotibialis. For example, in one case, the mean burst duration (mean $\pm \mathrm{SE}$ ) of the sartorius was $0.35 \pm 0.038$ versus $0.95 \pm 0.046 \mathrm{sec}$. In two other cases, the sartorius durations were $0.28 \pm 0.024$ and $0.20 \pm 0.014$ versus $1.05 \pm 0.05$ and $1.06 \pm 0.03 \mathrm{sec}$ for the femorotibialis. In general, extensor pools, such as the femorotibialis or ischioflexorius/caudilioflexorius, had burst durations of $\sim 1 \mathrm{sec}$, whereas flexor pools, such as the sartorius, had burst durations between 200 and $350 \mathrm{msec}$. Throughout the figure legends, the sartorius burst will be shown on the bottom trace paired with a femorotibialis burst on the top trace, unless otherwise noted. As at stage 24, a single stimulus to the rostral cord (cervical or thoracic) elicited a single burst (Fig. 2E, arrow) that was very similar to that occurring spontaneously (Fig. $2 A$ ).

To determine whether this early activity was generated by a network of synaptically connected neurons or alternatively represented pacemaker-like activity of electrically coupled neurons, we bathed the embryo in Tyrode's solution with altered calcium $\left(\mathrm{Ca}^{2+}\right)$ and magnesium $\left(\mathrm{Mg}^{2+}\right)$ levels $\left(0.2 \mathrm{mM} \mathrm{Ca}^{2+} / 7 \mathrm{mM} \mathrm{Mg}^{2+}\right.$ or $\left.2 \mathrm{mM} \mathrm{Ca}^{2+} / 12 \mathrm{mM} \mathrm{Mg}^{2+}\right)$ to selectively block chemical transmission. Under these conditions, spontaneous bursts of activity ceased, although spontaneous unit activity was still present (data 
not shown). Low-calcium solution also inhibited our ability to elicit bursting by stimulation of the rostral cord (Fig. $2 F$, top trace, arrows mark stimulus artifacts), indicating that descending input drives the spinal circuit via chemical synapses. However, by positioning the stimulating electrode over the lateral motor column at the appropriate level, it was possible to directly activate the motoneurons, producing a large compound action potential in the muscle nerve (Fig. $2 F$, bottom trace, arrow marks stimulus). Such stimulation, however, did not elicit bursts. Blockade of bursting was reversed by returning to normal Tyrode's solution (3 $\left.\mathrm{mm} \mathrm{Ca}{ }^{2+} / 1 \mathrm{~mm} \mathrm{Mg}^{2+}\right)$. These results suggest that early bursting activity is generated by a synaptically connected network of neurons in the spinal cord and can be driven by descending input from more rostral cord levels.

Within a few hours of development (stage 25.5), two bursts of activity began to occur in each spontaneous episode (Fig. 2B), indicating that the circuit was now capable of generating more than one cycle of activity per episode, although the interburst interval varied considerably between episodes. In addition, the differences between the patterns of activity in different nerves became more pronounced (Fig. 2, compare $A, B$ ). However, the frequency of episodes remained similar to that in early stage 25 embryos (Fig. 2G).

By stage 28 (E6), when motor axons first contact their targets (Landmesser, 1978), the frequency of spontaneous episodes had slowed to approximately one every 3-5 min (Fig. 2G). Each episode usually contained two bursts of activity spaced more regularly apart than at younger stages, but other characteristics of the bursting pattern remained similar (Fig. 2C). However, at stage 28.5 , both the pattern and frequency of spontaneous activity changed more dramatically. Episodes now occurred every 6-7 min and contained multiple (two to four) bursts (Fig. 2D, $G$ ). For the first time, burst duration began to increase, and, in some cases, flexors and extensors began to fire out of phase for a portion of each burst.

As summarized in Figure $2 G$, at all stages studied, the frequency of spontaneous bursting episodes occurred with great regularity, although the interepisode interval increased with increasing age. Interestingly, the greatest change in frequency and bursting characteristics occurred shortly after initial target contact, but whether target contact is necessary for these changes will require additional experiments.

\section{Pharmacology of the developing circuit driving spontaneous bursting}

The mechanisms underlying spontaneous rhythm generation in the spinal cord are not fully understood. At later stages of development (E10-E12), spontaneous activity of chick lumbosacral motoneurons appears to be driven primarily by excitatory connections, especially glutamate (Barry and O'Donovan, 1987; Chub and O'Donovan, 1998). Glutamate receptor blockers APV and CNQX were shown to shut off spontaneous bursting activity when bath applied to an in vitro spinal cord-hind limb preparation (Chub and O'Donovan, 1998). Inhibitory connections, on the other hand, were shown to be important for generating the structure of bursts, especially the alternation of flexors and extensors (Sernagor et al., 1995). However, this system exhibits considerable plasticity in that "inhibitory" circuits (GABA and glycine) were able to drive normal spontaneous activity after chronic blockade of excitatory (glutamate and $\mathrm{ACh}$ ) transmission (Chub and O'Donovan, 1998). To determine whether the earliest chick circuit displays similar pharmacology, we bath applied either blockers or agonists of neurotransmitter receptors and recorded the subsequent changes in spontaneous motor output.

\section{Glutamatergic transmission is not required for normal bursting activity}

The excitatory amino acid glutamate has been shown to stimulate patterned bursts of activity in a number of locomotor circuits, including chick. In many systems, the effect of glutamate can be mimicked by NMDA, an agonist of NMDA-type glutamate receptors, suggesting that glutamate drives activity in large part through activating NMDA receptors (Barry and O'Donovan, 1987; Kudo and Yamada, 1987; Hernandez et al., 1991; Soffe, 1996).

To determine whether NMDA receptors are also important in the early chick cord, we bath applied NMDA $(30 \mu \mathrm{M})$ to stages 25 and 28 isolated cord preparations while recording from specific muscle nerves (Fig. 3). Similar to observations in older (stage 36) chick cords (Barry and O'Donovan, 1987), NMDA elicited rhythmic bursting activity that continued for the duration (several minutes) of drug application (Fig. $3 B, D$ ). At stage 25, bursts induced by NMDA (Fig. $3 B$ ) were well formed and resembled control spontaneous bursts (Fig. $3 A$ ) in pattern and duration (Fig. 3 , right traces are expanded time base records of portions of the left traces). Flexors and extensors still burst synchronously, but more unit activity occurred between bursts (Fig. 3B, asterisk) than in control. After extended drug application, burst duration began to lengthen and look more ragged (Fig. 3B, right trace, last burst). This effect of NMDA was completely blocked in the presence of the NMDA receptor blocker APV $(100 \mu \mathrm{M})$ (Fig. $3 C)$. At stage 28 (Fig. 3D), NMDA-induced bursts occurred even more frequently than at stage 25 (Fig. 3B), and this effect was also blocked by 100 $\mu \mathrm{M}$ APV (data not shown).

Despite the presence of activatable NMDA receptors in these early circuits, application of APV alone did not affect the frequency (Fig. $4 F$ ) or the pattern (Fig. 3, compare $A, C$ ) of spontaneous activity at either stages 25 or 28 . Thus, although NMDA receptors are present and their activation evokes rhythmic stereotyped bursts of activity, they are not necessary for the normal generation of bursting at these early stages.

Endogenously released glutamate could also be acting via kainate-AMPA receptors, and bath application of $10 \mu \mathrm{m}$ kainate was able to induce bursting activity (Fig. $4 B$ ). The pattern of activity induced by kainate differed from that induced by NMDA in two ways. First, kainate induced only a few bursts of activity rather than the continuous bursting elicited by NMDA. Second, these bursts were then followed by a significant increase in background unit activity, especially in extensor motoneurons (Fig. 4B, asterisk), and the cessation of further bursting activity. Background activity remained pronounced during drug application but returned to baseline within 1-2 min after the onset of a wash in normal Tyrode's solution (data not shown). Bursting activity also returned shortly after the beginning of the rinse. To determine whether kainate receptors were necessary for normal spontaneous bursting, we treated embryos with $20 \mu \mathrm{M}$ CNQX, a selective kainate receptor blocker. CNQX did not affect the frequency of bursting at either stages 25 or 28 (Fig. $4 F$ ). However, in some cases, it did induce a slight inhibitory period in extensor bursts shortly after burst onset, which subsequently disappeared after washout of the drug (data not shown).

Because it remained possible that glutamate was acting through both NMDA and non-NMDA glutamate receptors and that blocking alone was insufficient to alter normal bursting, we 


\section{A control STAge 25}
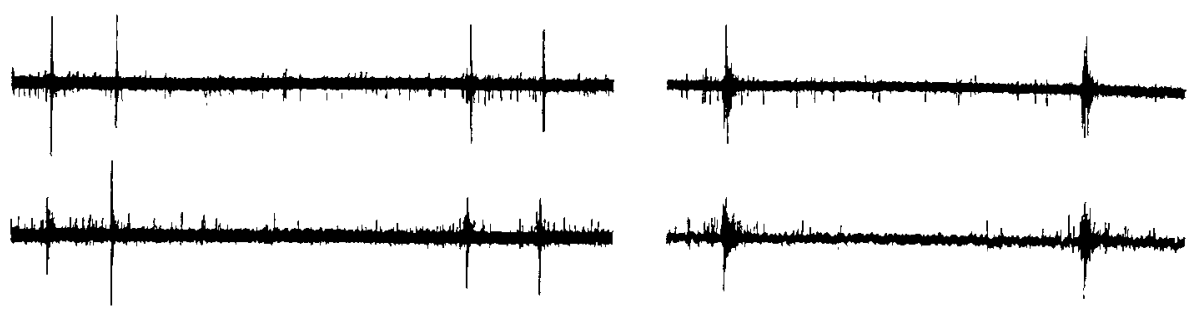

\section{B NMDA}
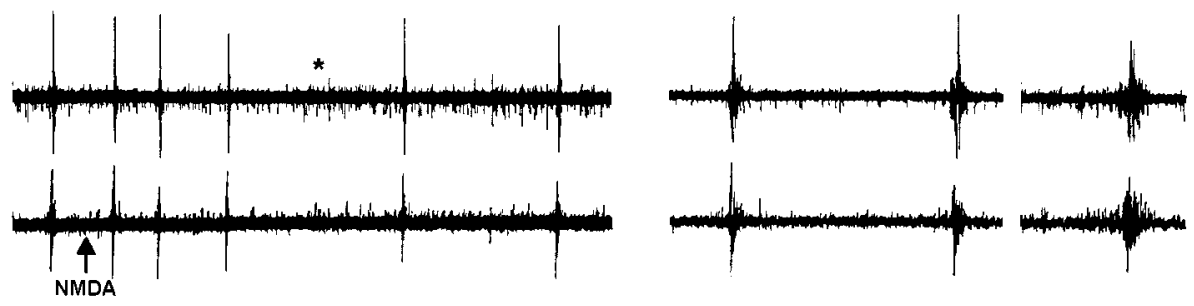

\section{APV + NMDA}


D STAge 28 NMDA
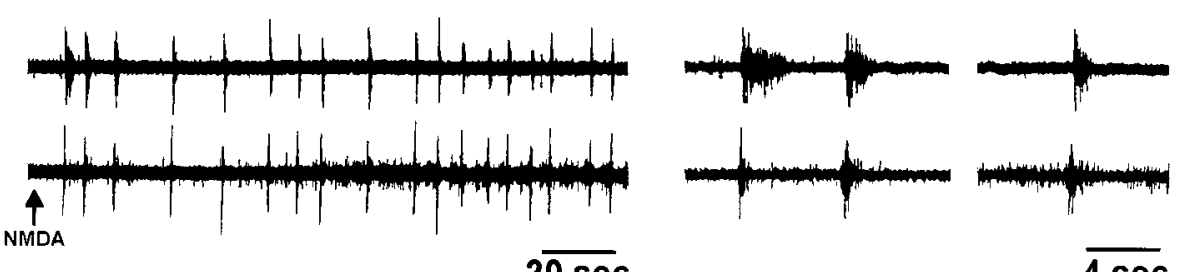

$\overline{20 \mathrm{sec}}$

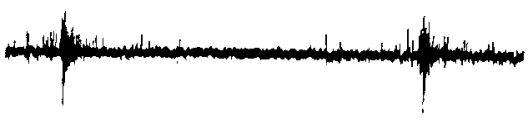

MDA blocked both with a combination of APV (100 $\mu \mathrm{M})$, CNQX (20 $\mu \mathrm{M})$, and in one case, kyurinate $(1 \mathrm{~mm})$. As seen in Figures 4 and 5 , this treatment did not significantly alter either the frequency of bursting (Fig. $4 F$ ) or the burst shape (Fig. 4, compare $C, D$ ). However, it did block the ability of kainate to induce multiple bursts (Fig. 4E, arrow marks addition of kainate to embryo pretreated with APV, CNQX, and kyurinate).

Finally, as an additional test of whether endogenously released glutamate was involved in locomotor activity, we bath applied DHK, which blocks the reuptake of glutamate at the synapse. We found that DHK $(200 \mu \mathrm{M})$ had no effect on the frequency (Fig. $4 F$ ) or pattern (data not shown) of spontaneous activity.

Together, these results demonstrate that although glutamate receptors are present in the spinal cord at early stages (E4-E5), they are not important for the initiation of rhythmic bursting. However, because CNQX induced a slight inhibitory period in extensor but not flexor bursts and treatment with the agonist
Figure 3. Activation of NMDA receptors elicits rhythmic bursting but is unnecessary for the generation of spontaneous bursting episodes. Traces on the left are shown at a slow time scale to demonstrate the effect of drug treatments on the frequency of bursting. Corresponding traces on the right show a subset of bursts on an expanded time scale to show details of the burst structure. Unlike control bursting $(A)$, application of $30 \mu \mathrm{M}$ NMDA at stage 25 (B, arrow) elicits multiple bursts of activity that continue for the duration of drug treatment. Initially, NMDA-induced bursts are well formed ( $B$, right, left two bursts) and resemble controls $(A$, right $)$. After prolonged NMDA exposure, unit activity increased $(B$, left, asterisk), and bursts increased in duration and looked more ragged $(B$, right, far right burst). $C$, Pretreatment with $100 \mu \mathrm{M}$ APV does not alter frequency or structure of spontaneous bursts (left and right) but does block the ability of NMDA to induce bursting (arrows mark application of NMDA). $A-C$ are from the same embryo. Top traces in each pair, FEMORO nerve. Bottom traces in each pair, obturator nerve. $D$, At stage 28, NMDA application induced more frequent bursting than at stage $25(B)$. NMDA bursts were also well formed $(D$, right $)$. In $D$, top traces are FEMORO nerves, and bottom traces are SART nerves. FEMORO, Femorotibialis; SART, sartorius. Calibration: $A-D$, left, 20 sec; right, 4 sec. kainate increased spontaneous background activity in extensors more than flexors, glutamate, acting through kainate-AMPA receptors, may play a minor role in the circuit responsible for generating burst shape, especially in extensor motor pools. Finally, because $1 \mathrm{~mm}$ glutamate was still able to induce several bursts, even in the presence of APV $(100 \mu \mathrm{M})$, CNQX $(20 \mu \mathrm{M})$, and kyurinate (1 $\mathrm{mm}$ ) (data not shown), glutamate receptors not blocked by these antagonists may be present. Nevertheless, in striking contrast to stage 36 (Chub and O'Donovan, 1998), blocking glutamate receptors at early stages with APV and CNQX did not have a significant effect on the generation of rhythmic bursting activity.

\section{Role of GABA in spontaneous bursting episodes}

At stage 36 , blockade of inhibitory transmission with the $\mathrm{GABA}_{\mathrm{A}}$ receptor blocker bicuculline and the glycine receptor blocker strychnine results in a reduction in the frequency and regularity 
A control stage 25

Figure 4. Activation of non-NMDA receptors by kainate induces bursting activity but is not necessary for the generation of spontaneous bursting episodes. Traces are from stage 25 embryos treated with kainate $(B, E)$, with $(D, E)$ or without $(B)$ glutamate receptor blockers. Addition of $10 \mu \mathrm{M}$ kainate $(B)$ induces a series of bursts that resemble control bursts $(A)$. Extended application causes an increase in unit activity, especially marked in extensor motoneurons (asterisk). Top traces in $A, B$, FEMORO nerve. Bottom traces in $A, B$, SART nerve. In another embryo, application of a cocktail of glutamate receptor blockers APV $(100 \mu \mathrm{M}), \mathrm{CNQX}(50$ $\mu \mathrm{M})$, and kyurinate (1 $\mathrm{mm})$ had no significant effect on bursting (compare with control in $C$ ) but did prevent kainate $(E$, arrow) from eliciting bursts. The burst in $E$ that follows kainate application was the second in a spontaneous episode and was not induced by kainate. $C-E$ are from one experiment. Top traces, FEMORO nerve; bottom traces, obturator nerve. Calibration: 2 sec. $F$, Bar graph showing the effect of glutamate drugs on frequency of spontaneous bursting episodes. Glutamate blockers APV, CNQX, and kyurinate have no significant effect on frequency of spontaneous bursting at stages 25 or 28 . Similarly, DHK, a glutamate uptake inhibitor, had no effect on bursting at stage 25 . Three separate experiments are shown, two at stage 25 and one at stage 28 (mean $\pm \mathrm{SE}$ ). $C$, Control. $\mathrm{APV}, 100 \mu \mathrm{M}$. CNQX, used at $50 \mu \mathrm{M}$ at stage $25,20 \mu \mathrm{M}$ at stage 28 . Kyurinate, 1 mM. DHK, $200 \mu \mathrm{M}$.

of spontaneous episodes, as well as a loss of flexor-extensor alternation (Sernagor et al., 1995; Chub and O'Donovan, 1998).

To test whether endogenous GABA circuits are also important for the frequency or pattern of early spontaneous activity, we first treated stages 25-29 embryos with the $\mathrm{GABA}_{\mathrm{A}}$ receptor antagonist bicuculline. Bath application of bicuculline $(50 \mu \mathrm{M})$ tended to slow the frequency of bursting episodes at both stages 25 and 28, although some variability was observed, with frequency in some cases increasing and in other cases decreasing or remaining unchanged (Fig. 6A). In all cases, however, the frequency of bursting episodes in the presence of bicuculline occurred at $\sim 5-7$ min intervals, regardless of the starting rate of control activity. Together, these observations indicate that by stage 25 , GABA circuits are present and can modulate patterned activity.

In contrast to its effect on frequency, bicuculline at stage $25 \mathrm{did}$ not appreciably affect burst structure (Fig. $5 A$ ). However, by stage 28 , bicuculline altered both the number and structure of bursts in each episode (Fig. 5B). First, it prevented the generation of multiple bursts; regardless of the number of bursts generated in control Tyrode's solution, only one burst per episode occurred in the presence of bicuculline (Fig. $5 B$ ). Second, unlike controls, bursts appeared triangular in shape and were longer in duration.
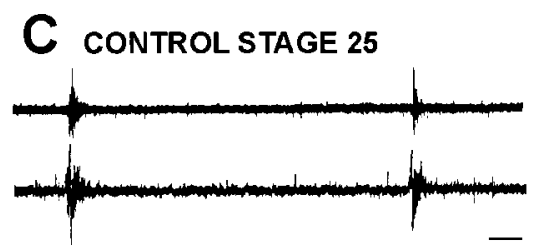

D APV + CNQX + KYURINATE

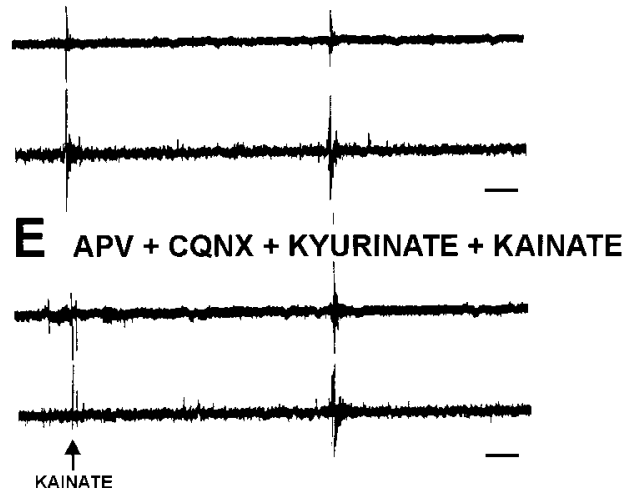

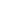
BURSTING EPISODES 

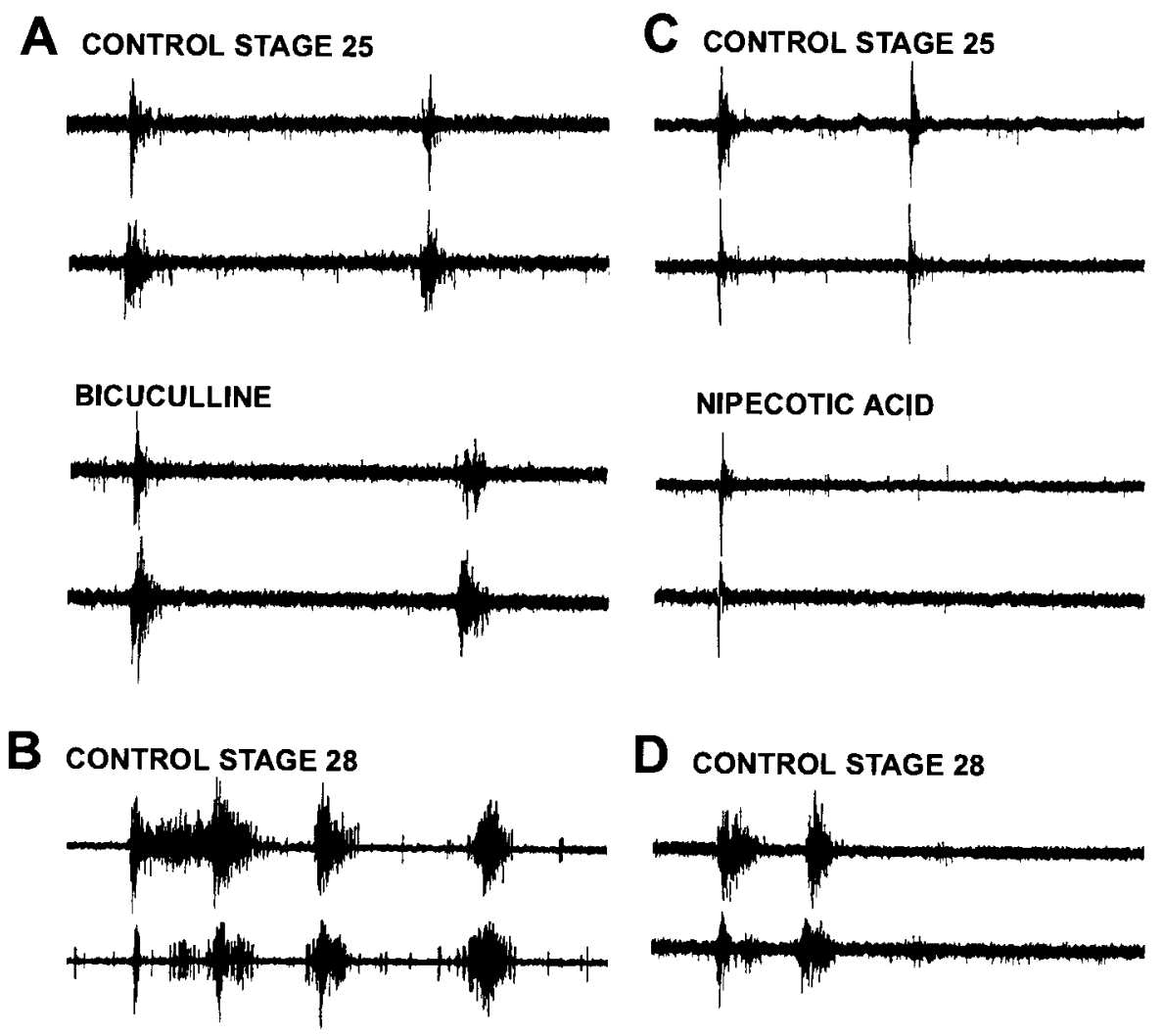

D control STAGE 28

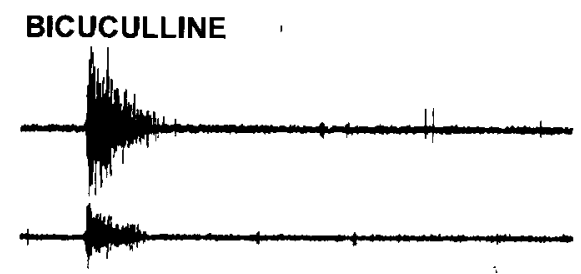



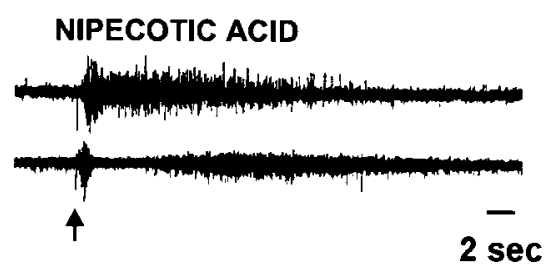

E MUSCIMOL
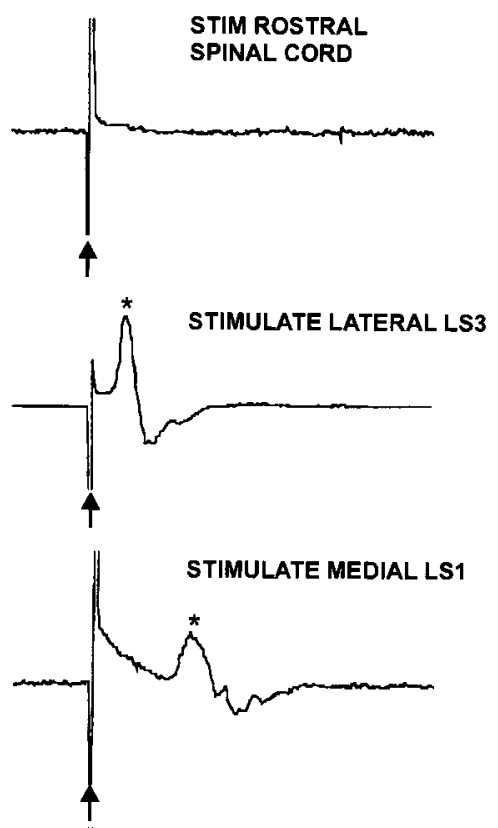

RESPONSE BLOCKED AT $1 \mathrm{~Hz}$

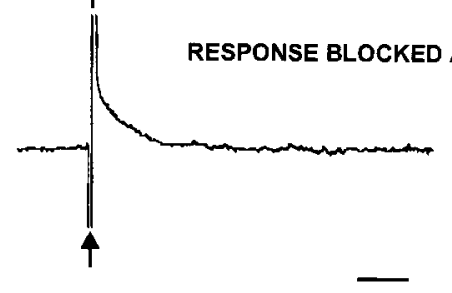

$5 \mathrm{msec}$

Figure 5. Effect of GABA agonists and antagonists on the pattern of spontaneous bursting. $A$, Bicuculline $(50 \mu \mathrm{M})$ has little effect on the structure or pattern of bursting at stage 25 (top trace in each pair, SART nerve; bottom trace in each pair, obturator nerve). However, at stage 28 (B), bicuculline prevented the generation of multiple bursts in an episode and altered the burst structure, which became triangular in shape (top traces in each pair, FEMORO nerves; bottom traces in each pair, SART nerves). $C$, At stage 25 , episodes in the presence of nipecotic acid (1 mM) contained only a single burst, which was, however, of similar duration to control bursts (top traces in each pair, FEMORO nerves; bottom traces in each pair, obturator nerves). $D$, At stage 28, although nipecotic acid prevented spontaneous bursting (see Fig. 6 B, open circles), a burst could still be elicited by stimulation of the rostral spinal cord (Fig. 5D, arrow, bottom traces). However, in contrast to stage $25(C)$, burst structure was markedly altered and considerably lengthened. In addition, flexor pools, such as the sartorius (bottom trace in each pair), exhibited a long period of quiescence after initial activation, after which they resumed bursting. Such a quiescent period did not occur in extensor pools (top trace in each pair, FEMORO). E, In the presence of $5 \mu \mathrm{M}$ muscimol, a $\mathrm{GABA}_{\mathrm{A}}$ agonist, stimulation of rostral cord (top trace, arrow marks stimulus artifact) no longer elicits a burst in the FEMORO nerve. However, a compound action potential in this nerve was produced by stimulation directly over the motor pool in LS3 (second trace, asterisk). FEMORO motoneurons could also be activated synaptically by cord stimulation of LS1 (third trace, asterisk). This synaptic response could be blocked by a train of stimuli at 1 $\mathrm{Hz}$ (fourth trace, arrow marks stimulus) and in other experiments by low-Ca ${ }^{+2}$ Tyrode's solution (data not shown). FEMORO, Femorotibialis; SART, sartorius. Arrows mark stimulus artifacts in each trace where applicable. Calibration: $A-D, 2 \mathrm{sec}, E, 5 \mathrm{msec}$.

inhibitory period after the onset of the burst (Fig. 5D, bottom, bottom trace), whereas extensors did not (Fig. 5D, bottom, top trace). These results suggest that GABAergic connections influencing flexor and extensor bursts differ or that flexor and extensor motoneurons respond differently to exogenously released GABA. The blocking effect of nipecotic acid on spontaneous activity was reversed quickly (within $3 \mathrm{~min}$ ) after return to normal Tyrode's solution, and bursting rebounded at an accelerated rate (interval between episodes, $40 \mathrm{sec}$ vs $4-5 \mathrm{~min}$ in controls) for the first hour of wash before returning to control levels (data not shown). Together, these observations show that GABA can modulate motoneuron activity even at stage 25 and that its role in pattern generation increases and changes with increasing embryonic age.
To confirm that $\mathrm{GABA}_{\mathrm{A}}$ receptors were present in the cord at stages 25 and 28, we treated embryos with muscimol, a $\mathrm{GABA}_{\mathrm{A}}$ agonist. At both stages, muscimol blocked spontaneous bursting, and activity did not resume until washout of the drug (data not shown). Muscimol treatment differed from nipecotic acid treatment in that muscimol sometimes stimulated a series of bursts before shutting off activity (data not shown). This was followed by a transient increase in background unit activity lasting several minutes, after which spontaneous bursting ceased. At this point, bursts could no longer be evoked by electrical stimulation to the rostral cord (Fig. 5E, top trace). However, stimulation directly over the lumbar lateral cord, although not eliciting a burst, directly activated motoneurons, producing a large short latency 
A

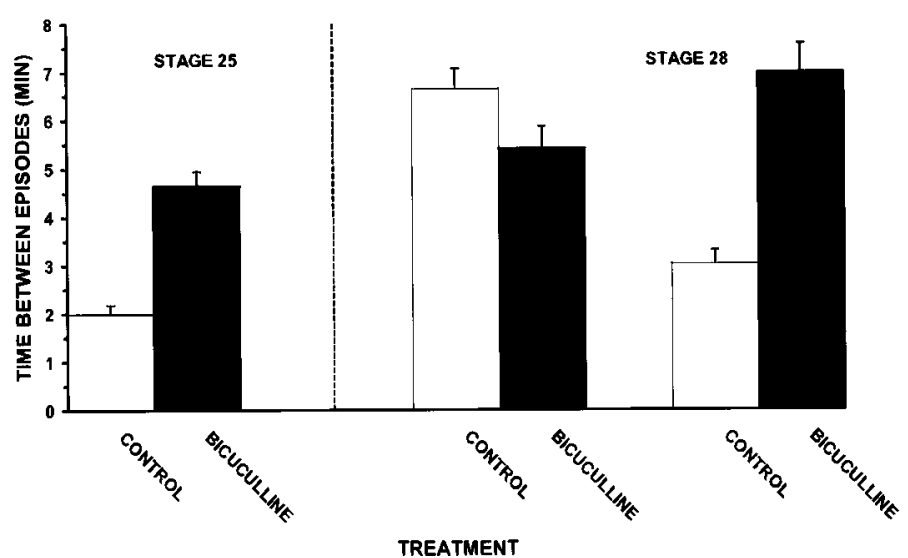

B
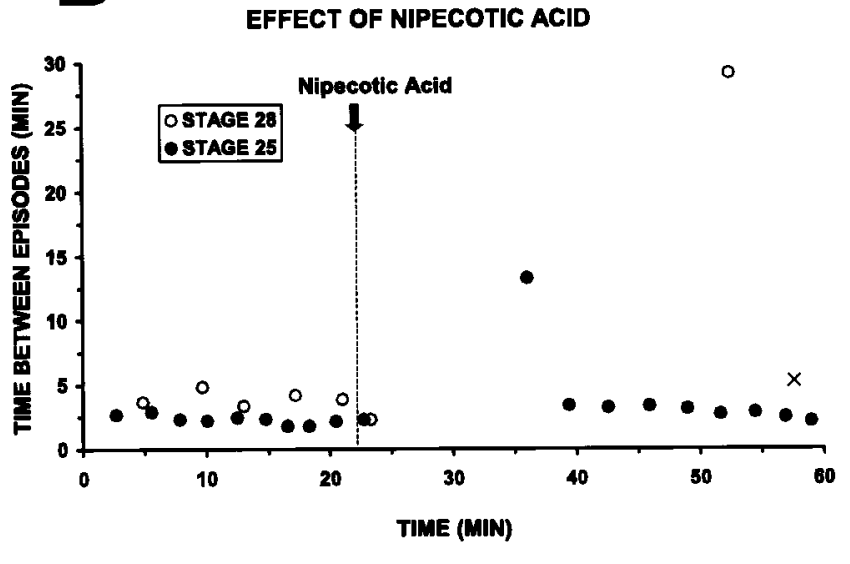

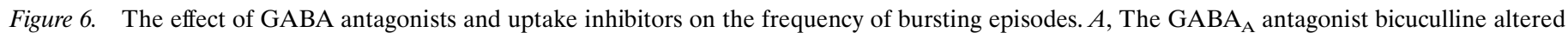
the frequency of bursting episodes at both stages 25 and 28, in some cases decreasing and in others increasing the interval between episodes. The bar graphs show the results from three separate embryos, and data are presented as mean \pm SE interval. $B$, The effect of 1 mM nipecotic acid (a GABA uptake inhibitor) on the interval between bursting episodes at stages 25 ( filled circles) and 28 (open circles). In both cases, activity was blocked, but it resumed after 25 min at stage 25 , whereas at stage 28 , only one spontaneous episode occurred (open circle) during prolonged nipecotic acid exposure. Such "single" spontaneous bursts that occasionally occurred during 1 or more hour of drug application may actually have been set off by extrinsic stimuli. Because bursts could still be evoked by stimulation of descending input in nipecotic acid, it is possible that this single burst might have resulted from some stimulated activation of the cord generator and may not reflect spontaneous activity. Arrow and dashed line show addition of nipecotic acid to the bath. The $x$ symbol marks an episode that was induced by electrical stimulation of the rostral spinal cord of the stage 28 embryo.

compound action potential in the muscle nerve (Fig. 5E, second trace, asterisk). Motoneurons could also be activated synaptically by stimulating the cord more medially. Stimulation at this site evoked a compound action potential (Fig. 5E, third trace, asterisk) of $6 \mathrm{msec}$ longer latency than that evoked by direct stimulation. Consistent with synaptic activation, this compound action potential recorded from the muscle nerve was blocked by $1 \mathrm{~Hz}$ stimulation (a frequency that blocks early synapses) (Fig. 5E, bottom trace) and by low $\mathrm{Ca}^{2+} /$ high $\mathrm{Mg}^{2+}$ Tyrode's solution (data not shown). In contrast, the compound action potential elicited by direct stimulation of the motoneurons was not blocked at $20 \mathrm{~Hz}$ stimulation nor by low $\mathrm{Ca}^{2+}$ Tyrode's solution (data not shown). The effects of muscimol were similar throughout stages 25-28, indicating that $\mathrm{GABA}_{\mathrm{A}}$ receptors are present at these stages and that their indiscriminate activation can disrupt spontaneous activity more severely than $\mathrm{GABA}_{\mathrm{A}}$ receptor antagonists or GABA reuptake blockers.

Despite the similarity in the effect of muscimol at stages 25 and 28 , the change in sensitivity to $\mathrm{GABA}_{\mathrm{A}}$ receptor blockers over this period indicates that the circuit responsible for generating rhythmic activity is changing and that GABA receptors are being used differently at these two stages in the developing locomotor circuit.

\section{Cholinergic input strongly modulates early spontaneous activity}

As shown above, neither blockade of glutamate nor GABA receptors with specific antagonists blocked recurrent spontaneous bursting activity in motoneurons, indicating that other transmitters must be involved in driving spontaneous activity. At later stages, both ACh and glycine have been shown to affect patterned activity (Sernagor et al., 1995), although they appear to play a minor role. Glycine, an inhibitory neurotransmitter, is not believed to be expressed by neurons in the cord until later stages of development (Berki et al., 1995). Acetylcholine, however, is the major excitatory transmitter in motoneurons, and if released centrally by motoneurons or interneurons, could provide excitatory drive to the network responsible for spontaneous bursting.

To test this hypothesis, we bath applied dTC, a nicotinic ACh receptor (nAChR) antagonist, at stages 25-29. At all stages tested, dTC $\left(5 \times 10^{-6} \mathrm{M}\right)$ transiently stopped spontaneous bursting activity (Fig. 7A), although bursting episodes could still be elicited by electrical stimulation of the descending input (data not shown). Interestingly, spontaneous bursting resumed after 10-25 min in the presence of drug, but at a lower frequency than control. The number and structure of bursts were also altered with the amplitude and number of bursts being increased in both flexor and extensor motoneurons (Fig. 7B,C). Extensors and flexors were differentially affected by dTC, with the burst duration of extensors being increased (Fig. 7C, top trace), whereas that of flexors was decreased (Fig. $7 C$, bottom trace). Furthermore, dTC appeared to increase the frequency of background unit activity in extensors more than flexors (data not shown), suggesting that cholinergic connectivity to extensors and flexors differs.

The response to dTC changed in a dose-dependent manner. At stage 28 , low concentrations of dTC $\left(5 \times 10^{-7} \mathrm{M}\right)$ did not shut off bursting but caused primarily an increase in the number of bursts per episode, with a slight change in the burst duration (Fig. 7C). At higher concentrations, dTC $\left(2-5 \times 10^{-6} \mathrm{M}\right)$ blocked spontaneous bursting for up to $40 \mathrm{~min}$ and had a more profound effect on burst duration. At the highest concentrations $\left(1 \times 10^{-5} \mathrm{M}\right)$, dTC blocked spontaneous activity for longer periods and continued to enhance burst amplitude and alter its duration (Fig. 7D). However, it also decreased the number of bursts per episode. Together, these results indicate that, at early developmental stages, nAChRs play a major role in regulating both the frequency and pattern of spontaneous motor activity.

To further test this hypothesis, we treated embryos with eserine, an acetylcholinesterase inhibitor, to block the degradation 


\section{A EFFECT OF DTC ON FREQUENCY OF SPONTANEOUS BURSTING EPISODES}
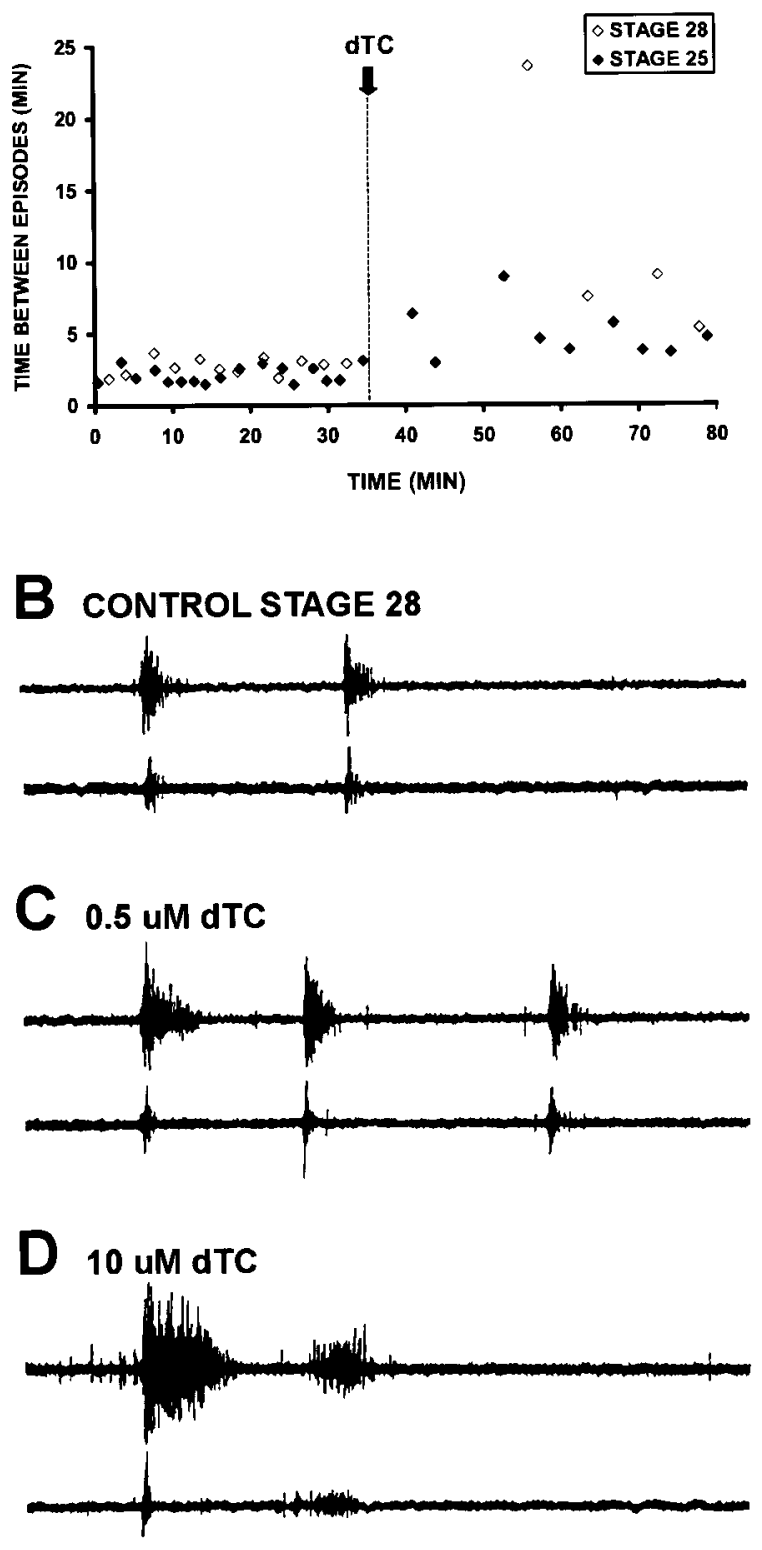

$\overline{2 \mathrm{sec}}$

Figure 7. Blocking nicotinic receptors alters both the frequency and pattern of spontaneous bursting activity. $A$, Graph plotting intervals (in minutes) between bursting episodes before and after the addition of $5 \mu \mathrm{M}$ dTC, a general blocker of nicotinic receptors. At both stages 25 ( filled diamonds) and 28 (open diamonds), dTC caused the cessation of spontaneous activity for a period of time; however, after prolonged exposure, bursting returned at a lower frequency (arrow and dashed line mark the addition of dTC). $B-D$, Effects of dTC on structure of bursting. Low doses $(0.5 \mu \mathrm{M})$ of dTC did not block spontaneous bursting (data not shown) but increased the number of bursts per episode and altered the burst duration and amplitude ( $C$, compare to control in $B$ ). Extensor bursts tended to increase in duration (top trace), whereas flexors decreased in duration (bottom trace). D, At high doses $(10 \mu \mathrm{M})$, dTC blocked spontaneous activity for over $20 \mathrm{~min}$, but after activity resumed bursts were enhanced in both amplitude and duration in extensors (top trace) and reduced slightly in duration in flexors (bottom trace). Interestingly, at high doses, there was a reduction in the number of bursts, some episodes only containing one burst as opposed to the normal two in controls $(B) . B-D$ are from a single stage 28 embryo. Top traces, FEMORO nerves; bottom traces, SART nerves. FEMORO, Femorotibialis; SART, sartorius. of endogenously released ACh. Eserine should thus enhance the action of any ACh released. Consistent with this, as shown in Figure 8, eserine had the opposite effect of cholinergic antagonists, such as dTC, on spontaneous bursting. First, eserine markedly increased the frequency of spontaneous bursting at both stages 25 and 28 (Fig. $8 A$ ). Second, whereas eserine did not affect burst structure at stage 25 (Fig. $8 C$ ), at stage 28, its affect on burst structure was quite profound (Fig. $8 B$ ). With each successive burst, presumably as ACh accumulated in the synapse, the two short bursts occurring at this stage were gradually replaced by a single burst of much longer duration ( $20 \mathrm{sec}$ compared with 1 sec in controls; see also Fig. $8 B$, bottom, traces on expanded time scale). It is interesting to note that the effect of eserine on burst shape and duration for flexors (sartorius; bottom trace of each pair) and extensors (femorotibialis; top trace of each pair) differed; flexor bursts tended to contain a long inhibitory period shortly after burst onset, whereas extensor bursts did not. These effects of eserine were blocked by pretreatment with dTC and atropine (data not shown), nicotinic and muscarinic receptor blockers, respectively, as would be expected if eserine were accentuating the effect of endogenously released ACh. The effect of enhancing the activity of endogenously released ACh (via eserine) on burst shape and duration was very similar to that produced by enhancing the effect of endogenously released GABA (via nipecotic acid) (compare Figs. $6 F, 8 B$ ). This might arise if one effect of $\mathrm{ACh}$ was to facilitate the release of GABA, a possibility considered further in Discussion.

\section{Acetylcholine acts primarily through non- $\alpha 7$ nicotinic receptors to modulate bursting}

Nicotinic receptors blocked by dTC are known to be a heterogeneous population composed of different subunit types (for review, see Role and Berg, 1996; Colquhoun and Patrick, 1997). The composition of subunits determines the kinetics, pharmacology, and ion specificity of the receptor. Two basic types of nicotinic AChRs have been described; homomeric $\alpha 7$ receptors and multimeric receptors that do not contain the $\alpha 7$ subunit but one of several other $\alpha$ subunits. $\alpha 7$ receptors differ from nicotinic receptors containing other $\alpha$ subunits in that they contain five subunits of the same type, are more permeable to calcium, and are specifically blocked by $\alpha$-bungarotoxin. However, more recent evidence indicates that $\alpha 7$ subunits may also participate in heteromeric receptors ( $\mathrm{Yu}$ and Role, 1998). In the present study, we have simply distinguished between receptors that are blocked by classical $\alpha 7$ blockers, such as $\alpha$-bungarotoxin and low doses of MLA, and those that are blocked by non- $\alpha 7$ blockers, such as DHBE. At later stages of development in the chick (stage 36), blockade of $\alpha 7$ receptors with $\alpha$-bungarotoxin has been shown to shut off activity (Landmesser and Szente, 1986). Thus, we were interested in whether early activity was similarly dependent on $\alpha 7$ receptor activation.

To distinguish between the effects of $\alpha 7$ and other nicotinic receptor subtypes, we treated embryos with more specific receptor blockers. The $\alpha 7$ blockers $\alpha$-bungarotoxin $(3 \mu \mathrm{g} / \mathrm{ml})$ and MLA (10 nM) had no significant effect on either the frequency of spontaneous bursting episodes (Fig. 9A) or the shape of bursts within an episode at either stages 25 or 28 (Fig. 9, compare $B, C$ ). MLA, however, did increase the number of bursts per episode at stage 25 (data not shown) but not at stage 28 . In contrast to these relatively minor effects, application of $1 \mu \mathrm{M}$ DHBE, which blocks a variety of nicotinic receptors containing $\alpha$ subunits other than $\alpha 7$, decreased the frequency of episodes at both stages 25 and 28 


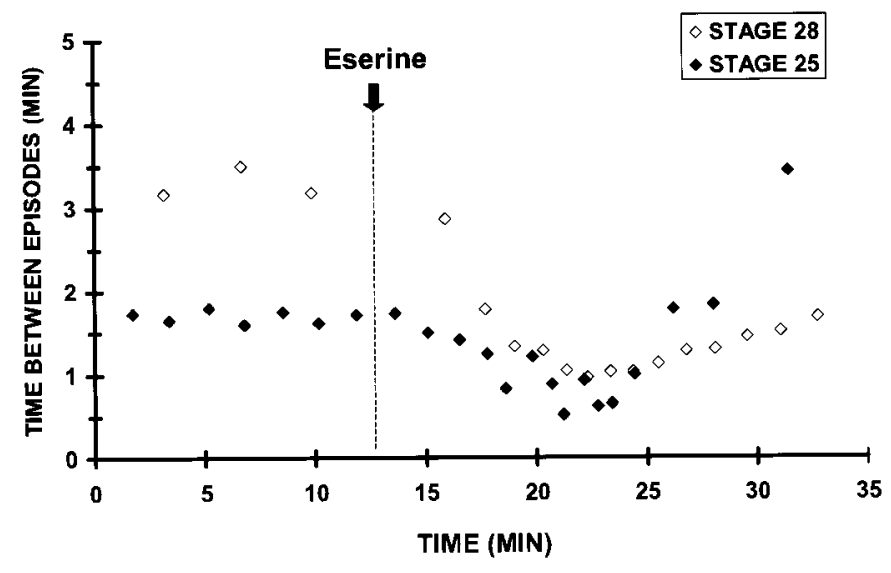



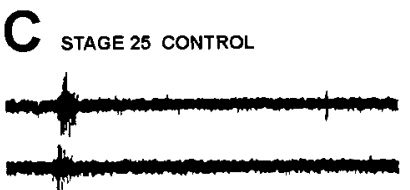

Figure 8. The acetylcholinesterase inhibitor eserine increases the frequency of spontaneous episodes and alters burst structure. $A$, Graph showing that eserine $(1 \mu \mathrm{M})$ increases the frequency of spontaneous episodes at both stages 25 (filled diamonds) and 28 (open diamonds). After prolonged exposure, episode frequency decreased in the presence of eserine, presumably as a result of ACh receptor desensitization. $B$, Eserine also altered the pattern of bursting in each episode. After eserine treatment, bursts became considerably elongated in duration (compare control bursting on left with bursting in eserine on right). In addition, flexors (bottom traces) were characterized by a period of quiescence shortly after onset of activity, whereas extensors (top traces) were not. Bottom panels in $B$ show representative bursts on an expanded time scale. $C$, Although eserine increased bursting frequency in both stages 25 and $28 \mathrm{em}$ bryos $(A)$, it did not alter bursting pattern at stage $25(C$, compare control on left with eserine on right). $B$, Top traces, FEMORO nerve recordings; bottom traces, SART nerve recordings. $D$, Top traces, Ischioflexorius nerve recordings; bottom traces, SART nerve recordings. FEMORO, Femorotibialis; SART, sartorius.
(Fig. 9A) and, like dTC, resulted in changes in burst shape, including an increase in burst amplitude and a change in burst duration (Fig. 9, compare $B, D$ ). DHBE also increased the number of bursts per episode at stage 28 but decreased the number at stage 25. Together, these results indicate that $\mathrm{ACh}$ is acting primarily through non- $\alpha 7$ nicotinic receptors to modulate both the frequency and pattern of spontaneous bursting activity.

\section{Low and high doses of nicotine affect spontaneous bursting differently}

In other parts of the nervous system, ACh has been shown to act via many different receptor subtypes, which have different affinities for agonists, antagonists, and differing rates of desensitization (McGhee and Role, 1995; Colquhoun and Patrick, 1997; Fenster et al., 1997). Some are located presynaptically and mod- ulate the release of transmitters, including GABA (for review, see Role and Berg, 1996; McMahon et al., 1994; McGehee et al., 1995; Lena and Changeux, 1997; Guo et al., 1998), whereas others are located postysnaptically and mediate classical fast transmission (McGehee et al., 1995; Role and Berg, 1996; Roerig et al., 1997). Although preliminary, the effects of nicotine that we observed on spontaneous motoneuron bursting suggest that in the early embryonic cord ACh is probably acting at several different sites via different receptor subtypes.

We found that high doses of nicotine $(10 \mu \mathrm{M})$ induced a series of bursts, followed by an increase in spontaneous unit activity (Fig. 10A). As this unit activity returned to baseline, spontaneous bursting ceased for at least $1 \mathrm{hr}$ (the duration of the drug application). This may have resulted from ACh receptor desensitiza- 
A

EFFECT OF ACH RECEPTOR BLOCKERS
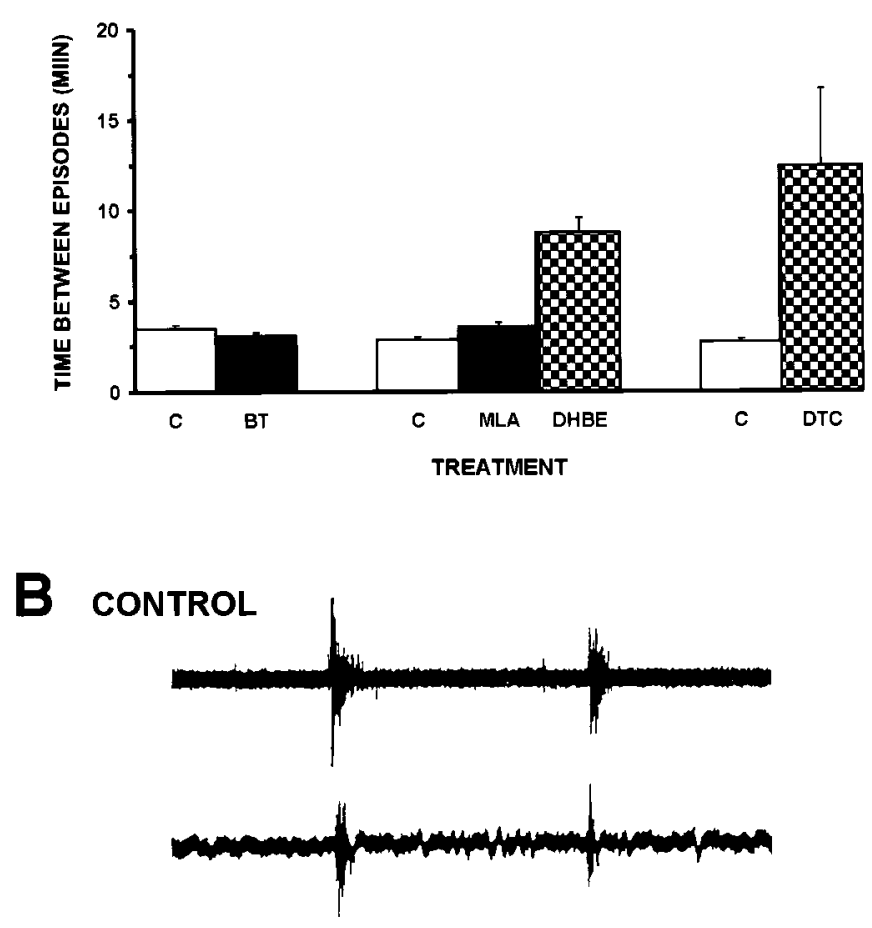

\section{MLA}
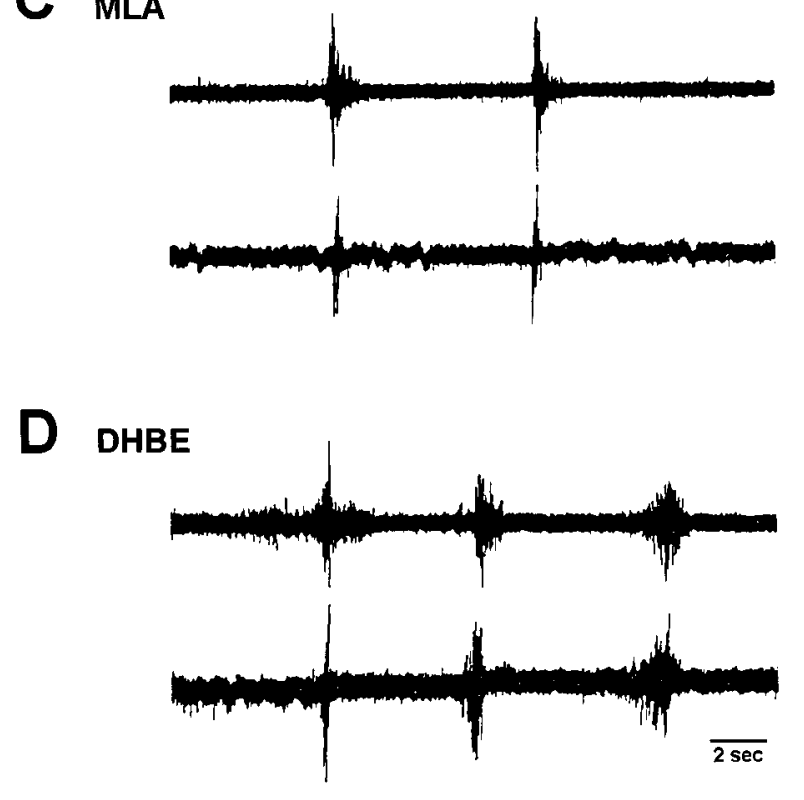

Figure 9. Acetylcholine acts primarily through non- $\alpha 7$ nicotinic receptors to regulate spontaneous bursting. $A$, Specific $\alpha 7$ blockers $\alpha$-bungarotoxin $(B T, 3 \mu \mathrm{g} / \mathrm{ml})$ and methyllycoconitine ( $M L A, 10 \mathrm{nM})$ have little or no effect on burst frequency (graph shows mean $\pm \mathrm{SE}$ ); DHBE and dTC are statistically different from control; $p=0.001$. However, dihydro-B-erythroidine (DHBE, $1 \mu \mathrm{M})$, which blocks non- $\alpha 7$-containing nicotinic receptors, shuts off bursting transiently, much like dTC, which binds both $\alpha 7$ and non- $\alpha 7$ receptors. $B-D, \alpha 7$ blockers have no significant effect on burst shape (compare bursts with 10 nM MLA in $C$ with controls in $B$ ) However, $1 \mu \mathrm{M}$ DHBE $(D)$ increased the amplitude and number of bursts per episode and also increased burst duration. Top traces, Caudilioflexorius nerve; bottom traces, sartorius nerve. Calibration: 2 sec. tion, which is common in many receptor subtypes especially at high agonist concentrations (Fenster et al., 1997). In contrast, much lower doses of nicotine $(0.1 \mu \mathrm{M})$ blocked spontaneous bursting without first inducing bursts or obvious activation of motoneurons. In both cases, a normally formed burst could still be elicited by stimulation of descending input, suggesting that the effects of nicotine in blocking spontaneous bursting are upstream of the circuit that actually generates the burst. The blockade of bursting produced by low nicotine $(0.1 \mu \mathrm{M})$ could be prevented by previous incubation with DHBE $(1 \mu \mathrm{M})$ but not by $\alpha$-bungarotoxin $(3 \mu \mathrm{g} / \mathrm{ml})$ (Fig. 10B), indicating that these effects are mediated by non- $\alpha 7$ receptors. The nicotine-induced blockade of bursting could also be prevented by previous incubation with bicuculline. Together, these results are consistent with ACh being able to act via high-affinity receptors to enhance GABA release. Given the complexity of the circuit and the likelihood that ACh is acting at multiple sites, the precise cellular mechanisms for the observed effects of nicotine remain unclear. However, the doses of nicotine that block spontaneous patterned activity of this developing spinal circuit are levels that would be expected to occur in the fetus after maternal cigarette smoking (Lambers and Clark, 1996).

\section{Early spontaneous bursting may be driven by either cholinergic or GABAergic circuits}

Thus far, we have shown that both cholinergic and GABAergic, but not glutamatergic, neurons are important for early spontaneous motoneuron bursting in the chick. However, in all cases in which the action of a neurotransmitter was blocked by receptor antagonists, spontaneous bursting activity recovered in the continued presence of the $\operatorname{drug}(\mathrm{s})$, presumably now driven by a different transmitter system. At stage 36, for example, recovery of spontaneous activity can occur after blockade of excitatory transmission (Chub and O'Donovan, 1998). In this situation, activity is now driven by the inhibitory transmitters (GABA and glycine), which can be depolarizing at early developmental stages (Cherubini et al., 1991; Owens et al., 1996; Rohrbough and Spitzer, 1996). However, simultaneous blockade of glutamate and GABA receptors resulted in complete activity blockade, reversible only by drug removal (Chub and O’Donovan, 1998).

To determine which transmitter systems were capable of driving spontaneous activity at stage 25 , we treated embryos with combinations of drugs. As shown for one embryo in Figure $11 A$, blockade of both GABA and glutamate receptors had no effect on spontaneous activity, in contrast to its effect at stage 36 (Chub and O'Donovan, 1998). Addition of dTC to these drugs resulted in a transient blockade of activity. However, activity resumed, and it was not until the addition of atropine to block muscarinic ACh receptors that spontaneous bursting activity ceased completely. In this case, bursting recovered quickly, within $3 \mathrm{~min}$, after the drugs were rinsed out in normal Tyrode's solution (Fig. $11 A)$.

To determine which of the transmitter systems was the most critical for spontaneous bursting, we next treated with a combination of cholinergic and GABAergic drugs. We found that spontaneous bursting activity was blocked completely in the presence of the cholinergic blockers atropine and dTC and the $\mathrm{GABA}_{\mathrm{A}}$ blocker bicuculline (Fig. 11B). These results indicate that spontaneous activity can be driven by either cholinergic or GABAergic circuits acting through $\mathrm{GABA}_{\mathrm{A}}$ receptors and that simultaneous blockade of both systems eliminates spontaneous activity. 
A Nicotine (10 uM)

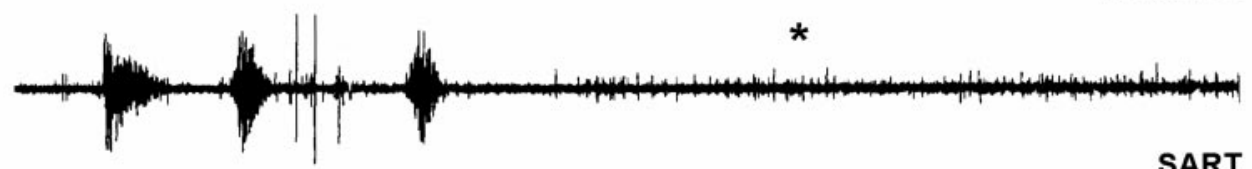

SART

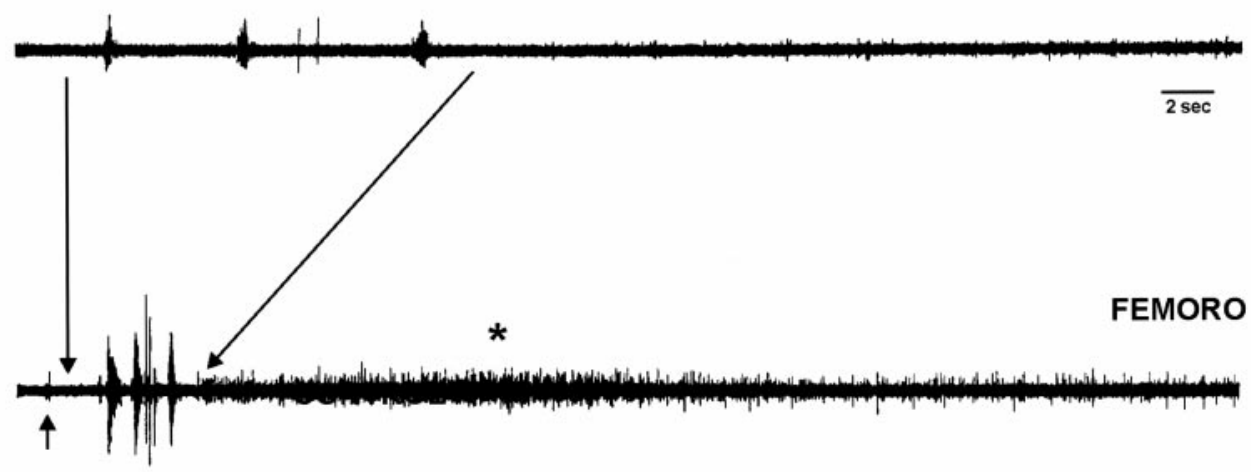

SART

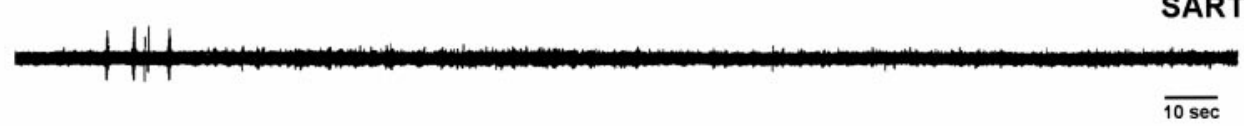

\section{B \\ EFFECT OF LOW NICOTINE ON FREQUENCY OF SPONTANEOUS BURSTING EPISODES}

Figure 10. Effect of nicotine on spontaneous bursting. $A$, At stage 28 , high doses of nicotine $(10 \mu \mathrm{M})$ induce a series of bursts (bottom traces, arrow marks addition of nicotine), followed by a transient increase in unit activity (asterisk). Top traces show bursting induced by high nicotine on an expanded time scale to demonstrate bursting characteristics. $B$, In contrast, low concentrations of nicotine $(0.1 \mu \mathrm{M})$ cause the cessation of spontaneous bursting. Pretreatment of embryos for 30 min with DHBE $(1 \mu \mathrm{M})$, but not $\alpha$-bungarotoxin $(3 \mu \mathrm{g} / \mathrm{ml})$, prevent the blockade of activity after low-nicotine treatment. In addition, pretreatment with bicuculline $(50 \mu \mathrm{M})$ to block $\mathrm{GABA}_{\mathrm{A}}$ receptors also prevents activity blockade by low nicotine. FEMORO, Femorotibialis; $S A R T$, sartorius.

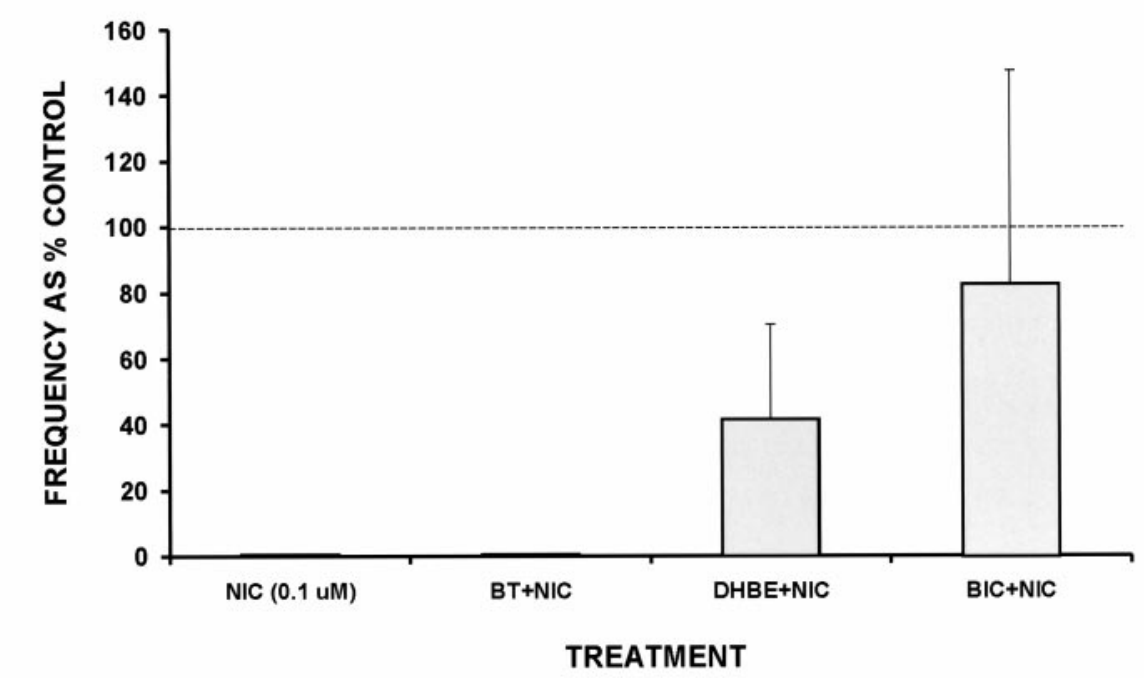

\section{Descending input}

Despite our ability to block spontaneous activity with cocktails of receptor blockers, we were unable to block the ability of rostral cord stimulation to elicit a bursting episode. For example, in the experiment shown in Figure $11 A$, we were still able to evoke a burst by electrical stimulation of the rostral cord ( $x$ symbols indicate stimulated bursts), even when spontaneous activity was completely shut off (Fig. 11C, arrow marks stimulus). Two mechanisms could explain this finding. Descending input could use a different transmitter, such as norepinephrine, serotonin, or dopamine, to activate local circuits in the lumbosacral spinal cord that generate bursts. Alternatively, the drugs used might not fully block all GABA, glutamate, and ACh receptors, possibly because of different affinities for embryonic forms of the receptors. This finding also suggests the possibility that another transmitter is involved in the local pattern generator circuit, because blockade of GABA, glutamate, and $\mathrm{ACh}$ receptors did not eliminate the ability of descending input, to stimulate a well formed burst of motoneuron activity (Fig. 11C). Another possibility, that electrical coupling between networks of motoneurons could produce bursts when activated by descending input, will be considered next.

\section{Potential role for electrical coupling in spontaneous burst generation}

Our observations have clearly demonstrated the importance of chemical transmission in allowing patterned spontaneous bursting by early lumbosacral motoneuron pools. They do not, however, preclude a role for electrical coupling between motoneurons or interneurons in generating the spontaneous bursting episodes. 


\section{A EFFECT OF RECEPTOR BLOCKERS ON FREQUENCY OF SPONTANEOUS BURSTING EPISODES}



\section{B \\ EFFECT OF BLOCKERS ON FREQUENCY OF SPONTANEOUS BURSTING EPISODES}
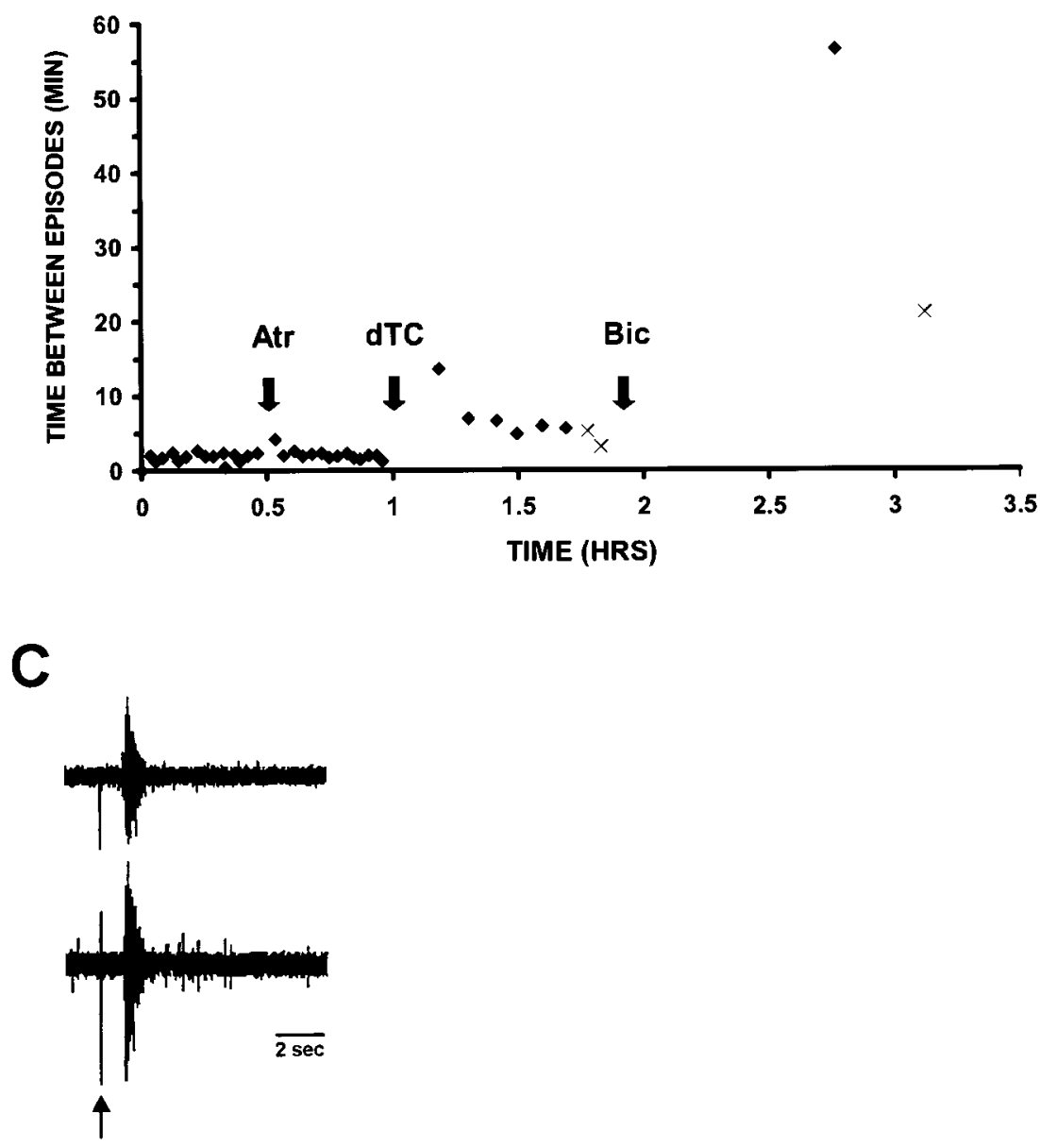

Electrical coupling has been demonstrated between somatic motoneurons in Xenopus embryos (Perrins and Roberts 1995a,b) and in neonatal rats (Walton and Navarette, 1991) and between preganglionic motoneurons (Logan et al., 1996) in rat lumbar cord. Several of our observations, although preliminary, are consistent with a role for electrical coupling via gap junctions in spontaneous burst generation.

Octanol (3 mM), which blocks gap junction-mediated electrical
Figure 11. Spontaneous activity at stage 25 does not occur after blockade of both excitatory and inhibitory connections. Embryos were treated with a combination of receptor blockers to determine which transmitter systems were critical for spontaneous bursting. In each graph, arrows mark the addition of each receptor blocker. $A$, Blockade of GABA receptors with a combination of phaclofen $(P h, 50 \mu \mathrm{M})$ and bicuculline $(B i c, 50 \mu \mathrm{M})$ has no effect on the frequency of spontaneous episodes. Addition of glutamate receptor blockers APV [50 $\mu \mathrm{M}$ and increasing to $100 \mu \mathrm{M}(A P V+)]$ and $\mathrm{CNQX}$ $(20 \mu \mathrm{M})$ to the GABA receptor blockers also has no effect on activity. However, dTC $(5 \mu \mathrm{M})$ causes a transient cessation of spontaneous activity for 25 min, followed by a recovery of bursting. Bursting ceases completely after atropine $(1 \mu \mathrm{M})$ is added to the cocktail. Bursting resumes quickly (within 3 $\mathrm{min}$ ) to near control frequency after washing in normal Tyrode's solution (arrow marks onset of wash at hour 6 of the experiment). The $x$ symbols represent activity induced by electrical stimulation of the rostral cord, an example being shown in $C$. Such stimuli, which were used to determine whether descending input was able to elicit bursts under various drug applications, did not affect subsequent bursting or lack thereof. $B$, Shows that atropine (1 $\mu \mathrm{M})$ has no effect on burst frequency when applied alone (Atr, arrow), but addition of dTC $(5 \mu \mathrm{M})$ to atropine shuts off activity transiently, and bursting returns in the continued presence of both drugs. This resumed activity may be mediated by GABA, because the addition of bicuculline $(50 \mu \mathrm{M})$ to the cocktail shuts off activity completely. One burst did occur after $\sim 1 \mathrm{hr}$, but no other bursts occurred. $C$, Although no spontaneous activity occurred in the presence of GABAergic, glutamatergic, and cholinergic receptor blockers shown in $A$, bursting could be elicited by a single electrical stimulus to the rostral cord ( $C$, arrow marks the stimulus artifact) Each stimulus evoked a single well formed burst. coupling and which reduces the frequency of spontaneous $\mathrm{Ca}^{2+}$ transients in embryonic chick retina (Catsicas et al., 1998), reversibly abolished spontaneous bursting of stage 25 motoneurons for as long as it was present (data not shown). We were also unable to elicit a burst by stimulating descending input; stimulation of the lumbar cord also did not elicit a burst but did directly activate the motoneuron pool producing a large compound action potential similar to that shown in Figure $2 F$. Because in addition 
to blocking gap junctions octanol is known to increase inactivation of sodium channels (Elliot and Elliot, 1989), we also tested a more selective gap junction blocker, carbenoxolone (Draguhn et al., 1998; Leslie et al., 1998). At $100 \mu \mathrm{M}$, carbenoxolone also reversibly blocked spontaneous bursting of stage 25 motoneurons after $\sim 50 \mathrm{~min}$ (data not shown). Before block of spontaneous bursting, burst amplitude was increased. After washout, bursting recovered within $25 \mathrm{~min}$ to predrug levels. These observations suggest that motoneurons and/or interneurons may be electrically coupled at these stages and that electrical coupling may act in combination with synaptic drive to produce spontaneous bursting.

\section{DISCUSSION}

Our major finding is that as early as E4 (stages 24-25), 1-1.5 d after being born (Hollyday and Hamburger, 1977) and while their axons are sorting into muscle-specific fascicles at the limb base, chick lumbosacral motoneurons exhibit regular bursts of electrical activity that are primarily driven by chemical synapses. At later developmental stages (E10-E12), spontaneous activity in this circuit is driven by a network of local neurons, including interneurons and possibly motoneurons, which are interconnected via excitatory synapses (Sernagor et al., 1995: Chub and O’Donovan, 1998). When excitation reaches some threshold, the network is activated and drives the motoneurons in an episode of bursting (Chub and O'Donovan, 1998). This model can also account for many of our observations. However, in contrast to later stages when glutamate provides the main excitatory drive (Chub and O'Donovan, 1998), at early stages, this is provided by endogenously released $\mathrm{ACh}$ acting for the most part via nicotinic non- $\alpha 7$ receptors.

The circuit we have pharmacologically characterized has many similarities to the circuit that drives spontaneous waves of electrical activity in the developing retinas of both ferret (Meister et al., 1991; Wong et al., 1998; Feller et al., 1996) and chick (Catsicas et al., 1998). Thus, the properties of the early cord circuit will first be compared with spontaneous activity in other developing circuits. Next, we will consider possible roles for such early activity in developing spinal cord. Finally, the current view of how motoneuron subtype identity is specified (Tsuchida et al., 1994; Sockanathan and Jessell, 1998) will be considered in light of the very early differences in bursting activity found between different motoneuron pools.

\section{Similarities in early circuits that generate spontaneous activity}

Unlike the local domains of spontaneous activity in developing visual cortex that are propagated by second messenger spread through gap junctions (Kandler and Katz, 1998), both the waves of electrical activity that spread across developing retina (Meister et al., 1991; Penn et al., 1994; Feller et al., 1996; Catsicas et al., 1998; Wong et al., 1998) and the spontaneous bursting activity in spinal cord (Chub and O'Donovan, 1998; present results) require chemical transmission. Although some degree of electrical coupling may be needed for effective generation of spontaneous bursts (Penn et al., 1994; Catsicas et al., 1998: Wong et al., 1998; present results), early spontaneous activity in the ferret (Feller et al., 1996; Penn et al., 1998) and chick (Catsicas et al., 1998) retina and in E4-E6 chick spinal cord (present results) is strongly modulated by nicotinic transmission. Spontaneous bursting in E11-E12 mouse spinal cord also requires nicotinic transmission (S. Banerjee and L. T. Landmesser, unpublished observations).
Thus, nicotinic modulation of spontaneous activity in early developing circuits may be widespread (Role and Berg, 1996). In ferret retina (Feller et al., 1996: Penn et al. 1998) and early chick spinal cord, ACh affects spontaneous activity primarily through nicotinic receptors that are not blocked by $\alpha 7$ antagonists. Nevertheless, the fact that blockade of $\alpha 7$ receptors in stage 25 cords resulted in an extra burst per episode indicates that these receptors are being activated during early activity and could be playing various roles, including regulation of gene expression (Spitzer et al., 1993; Fields et al., 1997) via calcium influx (Rathouz et al., 1995).

What is the source of the ACh that drives activity in early cord circuits? The chick circuit is contained entirely within the ventral cord (Ho and O'Donovan, 1993), which at E4-E5 contains only motoneurons and a small population of interneurons. ACh, released from motoneuron collaterals, could provide excitatory drive to both interneurons and motoneurons. In embryonic $X e$ nopus cord, motoneurons synapse on interneurons and other motoneurons and contribute to the excitatory drive underlying fictive swimming (Perrins and Roberts, 1994, 1995a,b). Alternatively, more diffuse, paracrine-like release of ACh from motoneurons could be responsible given the small distances involved. In both cord (Oppenheim and Foelix, 1972) and retina (Hughes and LaVelle, 1974), spontaneous bursting occurs when few, if any, specialized synaptic contacts are evident. The other source would be from local interneurons; a potential candidate is the cholinergic partition cell (Phelps et al., 1990), which occurs early, is located within the ventral cord, and projects into the lateral motor column. Although cholinergic interneurons have not been described in early chick cord (Thiriet et al., 1992), the sensitivity of immunohistological methods may be inadequate to detect them.

GABAergic input is capable of driving spontaneous cord bursting when excitatory inputs are blocked at both E10-E12 (Chub and O'Donovan, 1998) and E4-E5 (present results). The likely source of this input is a transient population of GABAergic interneurons, which are abundant in ventral cord from E5-E12 (Berki et al., 1995). Within early Xenopus cord, different classes of neurons have widely different reversal potentials for GABA (Rohrbough and Spitzer, 1996). Thus, depending on the interneurons involved, GABA could be excitatory or inhibitory for portions of the circuit. We found that enhancement of GABAergic transmission by a GABA uptake inhibitor suppressed bursting, whereas GABAergic inputs were also capable of driving bursting when cholinergic inputs were blocked. Clearly, more detailed characterization via intracellular recording and cell labeling will be required to explain these observations and to elucidate the mechanism underlying the plasticity observed at both E4-E5 and E10-E12.

\section{Developmental switch in transmitter driving spontaneous activity}

We have shown that the transmitter driving spontaneous bursting in E4-E5 chick cord (stages 25-28) is ACh, whereas at later stages (E10-E12) it is glutamate (Chub and O'Donovan et al., 1998). This switch occurs by stage 32 (E8) (M. Usiak and L. T. Landmesser, unpublished observations) shortly after contact with target, suggesting that some signal from the target may trigger these changes. A similar switch seems to occur in chick retina, with early waves (E11) being driven by ACh (Catsicas et al., 1998), whereas later ones depend more on glutamate transmission (Wong et al., 1998). These similarities between cord and retina could be coincidental. Alternatively, downstream consequences 
of the activity driven by these different transmitters may differ and be relevant to the role that activity is playing in early circuit formation.

\section{Potential roles of early spontaneous activity}

Spontaneous electrical activity has generally been viewed as a means for refinement of connections once neurons reach their targets (for review, see Goodman and Shatz, 1993; Katz and Shatz, 1996). Spontaneous waves of retinal activity are required for eye-specific layer formation in the lateral geniculate (Shatz and Stryker, 1988; Penn et al., 1998), and specific patterns of activity are also required for refinement of connections elsewhere (Herrmann and Shatz, 1995; Ruthazer and Stryker, 1996; Weliky and Katz, 1997). What might be the role of activity while motor axons are growing to their targets? It could be required for regulating, perhaps differentially, the expression of genes encoding cell adhesion and recognition molecules (Fields et al., 1997), such as polysialic acid, whose expression is activity dependent and which is required for proper sorting out of axons into poolspecific fascicles in the plexus region (Fredette et al., 1993; Tang et al., 1994). ACh, released from motoneuron growth cones during bursts and acting on ACh receptors on the same or other growth cones (Pugh and Berg, 1994), could also influence axon growth and branching via alterations in intracellular calcium. Activity may also be required for early steps in the formation of circuits within the cord. Such possibilities could be tested by selectively blocking activity at early stages. We have recently found that blockade of cord activity with the GABA agoninst muscimol results in some motoneuron somas being located outside their proper pool position (our unpublished observations). Whether these reflect motoneurons that have made pathfinding errors or that have failed to migrate properly is under investigation.

\section{Early pool-specific activity patterns and the specification of motoneuron subtypes}

Recent studies have begun to define the genes that may be specifying subclasses of motoneurons. A combinatorial code of LIM gene expression distinguishes lateral and medial classes of limb-innervating motoneurons (Tsuchida et al., 1994; Sockanathan and Jessell, 1998). However, from early stage 25 (E4) sartorius and femorotibialis motoneuron pools, both members of the lateral class and thus not distinguishable by the LIM gene code, were found to have different burst durations and to respond differently to various drugs. Their axons were also already sorted into pool-specific fascicles. Thus, these pools must already be differentially expressing the cell surface molecules required for such distinct electrical activity patterns and pool-specific fasciculation. Recently, several Ets genes have been shown to be expressed in a pool-specific manner (Lin et al., 1998). If these or other genes are to be credible candidates for the initial specification of pool identity, they must be shown to be differentially expressed even before stage 25 . If not, they still might be specifying pool-specific attributes, such as muscle afferent connectivity as proposed previously (Lin et al., 1998). However, their poolrestricted expression patterns would then have to be explained by even earlier acting genes.

\section{REFERENCES}

Barry MJ, O’Donovan MJ (1987) The effects of excitatory amino acids and their antagonists on the generation of motor activity in the isolated chick spinal cord. Dev Brain Res 36:271-276.
Bekoff A (1976) Ontogeny of leg motor output in the chick embryo: a neural analysis. Brain Res 106:271-291.

Bekoff A, Stein PSG, Hamburger V (1975) Coordinated motor output in the hindlimb of the 7-day chick embryo. Proc Nat Acad Sci USA 72:1245-1248.

Berki ACS, O'Donovan MJ, Antal M (1995) Developmental expression of glycine immunoreactivity and its colocalization with GABA in the embryonic chick lumbosacral spinal cord. J Comp Neurol 362:583-596.

Catsicas M, Bonness V, Becker D, Mobbs P (1998) Spontaneous Ca ${ }^{2+}$ transients and their transmission in the developing chick retina. Curr Biol 8:283-286.

Cherubini E, Gaiarsa JL, Yehezkel B (1991) GABA: an excitatory transmitter in early postnatal life. Trends Neurosci 14:515-519.

Chub N, O'Donovan MJ (1998) Blockade and recovery of spontaneous rhythmic activity after application of neurotransmitter antagonists to spinal networks of the chick embryo. J Neurosci 18:294-306.

Colquhoun LM, Patrick JW (1997) Pharmacology of neuronal nicotinic acetylcholine receptor subtypes. Adv Pharmacol 39:191-220.

Dahm LM, Landmesser LT (1991) The regulation of synaptogenesis during normal development and following activity blockade. J Neurosci $11: 238-255$

Ding R, Jansen JKS, Laing NG, Tonnesen H (1983) The innervation of skeletal muscles in chickens curarized during early development. J Neurocytol 12:887-919.

Draguhn A, Traub RD, Schmitz A, Jefferys JGR (1998) Electrical coupling underlies high-frequency oscillations in the hippocampus in vitro. Nature 394:189-192.

Elliot AA, Elliot JR (1989) The role of inactivation in the effects of $n$-alkanols on the sodium current of cultured rat sensory neurones. J Physiol (Lond) 415:19-33.

Feller MB, Wellis DP, Stellwagen D, Werblin FS, Shatz CJ (1996) Requirement for cholinergic synaptic transmission in the propogation of spontaneous retinal waves. Science 272:1182-1187.

Fenster CP, Rains MF, Noerager B, Quick MW, Lester RA (1997) Influence of subunit composition on desensitization of neuronal acetylcholine receptors at low concentrations of nicotine. J Neurosci 17:5747-5759.

Fields RD, Eshete F, Stevens B, Itoh K (1997) Action potentialdependent regulation of gene expression: temporal specificity in $\mathrm{Ca}^{2+}$, cAMP-responsive element binding proteins, and mitogen-activated protein kinase signaling. J Neurosci 17:7252-7266.

Fredette B, Rutishauser U, Landmesser L (1993) Regulation and activity-dependence of $\mathrm{N}$-cadherin, NCAM isoforms, and polysialic acid on chick myotubes during development. J Cell Biol 123:1867-1888.

Fredette BJ, Landmesser LT (1991) A reevaluation of the role of innervation in primary and secondary myogenesis in developing chick muscle. Dev Biol 143:19-35.

Galli L, Maffei L (1988) Spontaneous impulse activity of rat retinal ganglion cells in prenatal life. Science 242:90-91.

Goodman CS, Shatz CJ (1993) Developmental mechanisms that generate precise patterns of neuronal connectivity. Cell [Suppl] 72:77-98.

Greensmith L, Vrbova G (1991) Neuromuscular contacts in the developing rat soleus depend on muscle activity. Dev Brain Res 62:121-129.

Guo J-Z, Tredway TL, Chiappinelli V (1998) Glutamate and GABA release are enhanced by different subtypes of presynaptic nicotinic receptors in the lateral geniculate nucleus. J Neurosci 18:1963-1969.

Hamburger V, Balaban M (1963) Observations and experiments on spontaneous rhythmical behavior in the chick embryo. Dev Biol 7:533-545.

Hamburger V, Hamilton HL (1951) A series of normal stages in the development of the chick embryo. J Morphol 88:49-82.

Hamburger V, Wenger E, Oppenheim R (1966) Motility in the chick embryo in the absence of sensory input. J Exp Zool 162:133-160.

Harris AJ (1981) Embryonic growth and innervation of rat skeletal muscles. I. Neural regulation of muscle fiber numbers. Phil Trans R Soc Lond B Biol Sci 293:257-277.

Hernandez P, Elbert K, Droge MH (1991) Spontaneous and NMDA evoked motor rhythms in the neonatal mouse spinal cord: an in vitro study with comparisons to in situ activity. Exp Brain Res 85:66-74.

Herrmann K, Shatz CJ (1995) Blockade of action potential activity alters initial arborization of thalamic axons within cortical layer 4. Proc Natl Acad Sci USA 92:11244-11248.

Ho S, O'Donovan MJ (1993) Regionalization and intersegmental coordination of rhythm-generating networks in the spinal cord of the chick embryo. J Neurosci 13:1354-1371. 
Hollyday M, Hamburger V (1977) An autoradiographic study of the formation of the lateral motor column in the chick embryo. Brain Res 132:197-208.

Hubel DH, Wiesel TN (1970) The period of susceptibility to the physiological effects of unilateral eye closure in kittens. J Physiol (Lond) 206:419-436.

Hughes WF, LaVelle A (1974) On the synaptogenic sequence in the chick retina. Anat Rec 179:297-302.

Kandler K, Katz LC (1998) Coordination of neuronal activity in developing visual cortex by gap junction-mediated biochemical communication. J Neurosci 18:1419-1427.

Katz LC, Shatz CJ (1996) Synaptic activity and the construction of cortical circuits. Science 274:1133-1138.

Kudo N, Yamada T (1987) N-Methyl-D,L-aspartate-induced locomotor activity in a spinal cord-hindlimb muscles preparation of the newborn rat studied in vitro. Neurosci Lett 75:43-48.

Lambers DS, Clark KE (1996) The maternal and fetal physiologic effects of nicotine. Semin Perinatol 20:115-126.

Landmesser L (1978) The development of motor projection patterns in the chick hind limb. J Physiol (Lond) 284:391-414.

Landmesser LT, O'Donovan MJ (1984) Activation patterns of embryonic chick hind limb muscles recorded in ovo and in an isolated spinal cord preparation. J Physiol (Lond) 347:189-204.

Landmesser LT, Szente M (1986) Activation patterns of embryonic chick hind-limb muscles following blockade of activity and motoneurone cell death. J Physiol (Lond) 380:157-174.

Lena C, Changeux J-P (1997) Role of $\mathrm{Ca}^{2+}$ ions in nicotinic facilitation of GABA release in mouse thalamus. J Neurosci 17:576-585.

Leslie J, Nolan MF, Spanswick D (1998) Actions of carbenoxolone on rat sympathetic preganglionic neurones in vitro. J Physiol (Lond) 506P:146.

Lin JH, Saito T, Anderson DJ, Lance-Jones C, Jessell TM, Arber S (1998) Coordinate expression of Ets domain proteins by functionally related motor neuron pool and muscle sensory afferent subtypes. Cell 95:817-828.

Logan SD, Pickering AE, Gibson IC, Nolan MF, Spanswick D (1996) Electrotonic coupling between rat sympathetic preganglionic neurones in vitro. J Physiol (Lond) 495:491-502.

McGehee DS, Role LW (1995) Physiological diversity of nicotinic acetylcholine receptors expressed by vertebrate neurons. Annu Rev Physiol 57:521-546.

McGehee DS, Heath MJS, Gelber S, Devay P, Role LW (1995) Nicotine enhancement of fast excitatory synaptic transmission in CNS by presynaptic receptors. Science 269:1692-1696.

McLennan IS (1983) Differentiation of muscle fiber types in the chicken hindlimb. Dev Biol 97:222-228.

McMahon LL, Yoon KW, Chiappinelli VA (1994) Nicotinic receptor activation facilitates GABAergic neurotransmission in the avian lateral spiriform nucleus. Neuroscience 59:689-698.

Meister M, Wong ROL, Baylor DA, Shatz CJ (1991) Synchronous bursts of action potentials in ganglion cells of the developing mammalian retina. Science 252:939-943.

Mooney R, Penn AA, Gallego R, Shatz CJ (1996) Thalamic relay of spontaneous retinal activity prior to vision. Neuron 17:863-874.

O'Brian RAD, Ostberg AJC, Vrbova G (1978) Observations on the elimination of polyneuronal innervation in developing mammalian skeletal muscle. J Physiol (Lond) 282:571-582.

O'Donovan MJ (1989) Motor activity in the isolated spinal cord of the chick embryo: synaptic drive and firing pattern of single motoneurons. J Neurosci 9:943-958.

O'Donovan MJ, Landmesser L (1987) The development of hindlimb motor activity studied in the isolated spinal cord of the chick embryo. J Neurosci 7:3256-3264.

Oppenheim RW, Foelix RF (1972) Synaptogenesis in the chick embryo spinal cord. Nat New Biol 235:126-128.

Owens DF, Boyce LH, Davis MBE, Kriegstein AR (1996) Excitatory GABA responses in embryonic and neonatal cortical slices demonstrated by gramicidin perforated-patch recordings and calcium imaging. J Neurosci 16:6414-6423.

Penn AA, Wong ROL, Shatz CJ (1994) Neuronal coupling in the developing mammalian retina. J Neurosci 14:3805-3815.

Penn AA, Riquelme PA, Feller MB, Shatz CJ (1998) Competition in retinogeniculate patterning driven by spontaneous activity. Science 279:2108-2112.

Perrins R, Roberts A (1994) Nicotinic ACh receptors provide excitation to interneurones of the spinal rhythm generator for swimming in Xenopus embryos. J Physiol (Lond) 477:50P-51P.

Perrins R, Roberts A (1995a) Cholinergic and electrical motoneuron-tomotoneuron synapses contribute to on-cycle excitation during swimming in Xenopus embryos. J Neurophysiol 73:1005-1012.

Perrins R, Roberts A (1995b) Cholinergic contribution to excitation in a spinal locomotor central pattern generator in Xenopus embryos. J Neurophysiol 73:1013-1019.

Phelps PE, Barber RP, Brennan LA, Maines VM, Salvaterra PM, Vaughan JE (1990) Embryonic development of four different subsets of cholinergic neurons in rat cervical spinal cord. J Comp Neurol 291:9-26.

Pugh PC, Berg DK (1994) Neuronal acetylcholine receptors that bind $\alpha$-bungarotoxin mediate neurite retraction in a calcium dependent manner. J Neurosci 14:889-896.

Rathouz MM, Vijayaraghavan S, Berg DK (1995) Acetylcholine differently affects intracellular calcium via nicotinic and muscarinic receptors on the same population of neurons. J Biol Chem 270:14366-14375.

Ripley KL, Provine RR (1972) Neural correlates of embryonic motility in the chick. Brain Res 45:127-134.

Roerig B, Nelson DA, Katz LC (1997) Fast synaptic signaling by nicotinic acetylcholine and serotonin 5-HT3 receptors in the developing visual cortex. J Neurosci 17:8353-8362.

Rohrbough J, Spitzer N (1996) Regulation of intracellular Cl- levels by $\mathrm{Na}^{+}$-dependent $\mathrm{Cl}$-cotransport distinguishes depolarizing from hyperpolarizing GABA receptor-mediated responses in spinal neurons. J Neurosci 16:82-91.

Role LW, Berg DK (1996) Nicotinic receptors in the development and modulation of CNS synapses. Neuron 16:1077-1085.

Ruthazer ES, Stryker MP (1996) The role of activity in the development of long-range horizontal connections in area 17 of the ferret. J Neurosci 16:7253-7269.

Sernagor E, Chub N, Ritter A, O'Donovan MJ (1995) Pharmacological characterization of the rhythmic synaptic drive onto lumbosacral motoneurons in the chick embryo spinal cord. J Neurosci 15:7452-7464.

Shatz CJ, Stryker MP (1988) Prenatal tetrodotoxin infusion blocks segregation of retinogeniculate afferents. Science 242:87-89.

Sockanathan S, Jessell TM (1998) Motor neuron-derived retinoid signaling specifies the subtype identity of spinal motor neurons. Cell 94:503-514.

Soffe SR (1996) Motor patterns for two distinct rhythmic behaviors evoked by excitatory amino acid agonists in the Xenopus embryo spinal cord. J Neurophysiol 75:1815-1825.

Spitzer NC, Debaca RC, Allen KA, Holliday J (1993) Calcium dependence of differentiation of GABA immunoreactivity in spinal neurons. J Comp Neurol 337:168-175.

Tang J, Rutishauser U, Landmesser L (1994) Polysialic acid regulates growth cone behavior during sorting of motor axons in the plexus region. Neuron 13:405-414.

Thiriet G, Kempf J, Ebel A (1992) Distribution of cholinergic neurons in the chick spinal cord during embryonic development. Comparison of ChAT immunocytochemistry with $\mathrm{AChE}$ histochemistry. Int $\mathrm{J}$ Dev Neurosci 10:459-466.

Thompson WJ (1985) Activity and synapse elimination at the neuromuscular junction. Cell Mol Neurobiol 5:167-182.

Tsuchida T, Ensini M, Morton SB, Baldassare M, Edlund T, Jessell TM, Pfaff SL (1994) Topographic organization of embryonic motor neurons defined by expression of LIM homeobox genes. Cell 79:957-970.

Walton KD, Navarette R (1991) Postnatal changes in motoneuron electrotonic coupling studied in the in vitro rat lumbar spinal cord. J Physiol (Lond) 433:283-305.

Weliky M, Katz LC (1997) Disruption of orientation tuning in visual cortex by artificially correlated neuronal activity. Nature 386:680-685

Wong WT, Sanes JR, Wong ROL (1998) Developmentally regulated spontaneous activity in the embryonic chick retina. J Neurosci 18:8839-8852.

Yu CR, Role LW (1998) Functional contribution of the a7 subunit to multiple subtypes of nicotinic receptors in embryonic chick sympathetic neurons. J Physiol (Lond) 509:651-665. 